\title{
Research on kinematics analysis of spherical single-cone PDC compound bit and rock breaking simulation verification
}

\author{
Chunyan Kong ${ }^{1, *}$, Rongjun Zhu ${ }^{1}$, Derong Zhang ${ }^{2}$, and Shuangshuang Li $^{1}$ \\ ${ }^{1}$ School of Mechanical Engineering, Xihua University, Chengdu, Sichuan 610039, PR China \\ ${ }^{2}$ School of Mechatronic Engineering, Southwest Petroleum University, Chengdu, Sichuan 610500, PR China
}

Received: 16 April 2021 / Accepted: 2 June 2021

\begin{abstract}
The single-cone bit has become the first choice for slim hole sidetracking and deep well drilling with its unique rock breaking method and high ROP (Rate Of Penetration), with its main failure mode being of early excessive wear of the cutting teeth. In order to improve the adaptability of single-cone bits to hard and highly abrasive formations, a spherical single-cone Polycrystalline Diamond Compact (PDC) compound bit is designed. According to the characteristics of the tooth profile, the way of tooth arrangement and the way of contact between the cutting teeth and the rock, the acceleration equation to the cutting teeth of the spherical single-cone PDC compound bit is established. The acceleration of the single-cone bit is verified by numerical simulation experiment of rock-breaking. The shaft inclination angle of the cone, the position and height of the PDC teeth, the radius of the PDC teeth, the lateral rotation angle and the front inclination angle on the acceleration are studied. The results show that as the shaft inclination angle increases, the bit transmission ratio gradually increases, and the harder the rock formation, the larger the transmission ratio of the single-cone bit; the shaft inclination angle and the position of the PDC tooth have a greater influence on the acceleration of the PDC tooth, and the radius, lateral rotation angle and front inclination angle of the PDC tooth have a small influence on the acceleration of the PDC tooth; rock properties have an impact on the acceleration of the cutting teeth, with the acceleration of the cutting teeth in hard rock formations being higher than that in soft rock formations; near the top of the cone, the absolute acceleration of the cutting teeth will fluctuate sharply and cause severe wear of the cutting teeth, so the tooth distribution in this area should be strengthened; on the premise that the bearing life of the single-cone bit is allowed, the value of the shaft inclination angle $\beta$ can be approached to $70^{\circ}$. The relative error between the theoretical analysis results of the acceleration of the PDC cutter and the rock-breaking simulation experiment results is between $-0.95 \%$ and $-2.24 \%$. This research lays a theoretical foundation for the dynamic research of spherical single-cone PDC compound bit.
\end{abstract}

\section{Nomenclature}

$\rho \quad$ Radius vector, as shown in Figure 6, mm;

$\theta \quad$ Polar angle, degree;

Z Vertical height, $\mathrm{mm}$;

$L \quad$ Distance from the center of the cone to the back cone plane of the cone, mm;

$h_{\mathrm{C}} \quad$ Position height of the center point $\mathrm{C}$ of the PDC cutting tooth surface, mm;

$r_{\mathrm{C}} \quad$ Radius of the characteristic circle where point $\mathrm{C}$ is located, mm;

$\alpha \quad$ Rotation angle of the cone relative to the cone shaft, degree; $\alpha_{0} \quad$ Initial rotation angle of the cone relative to the cone shaft, degree;

$x_{1}, y_{1}, z_{1}$ Coordinate value of point $\mathrm{Q}$ in the coordinate system $O_{1} X_{1} Y_{1} Z_{1}, \mathrm{~mm}$;

$r_{\mathrm{Q}} \quad$ Radius of PDC cutter, mm;

$\beta \quad$ Shaft inclination angle of single-cone bit, degree;

$\theta \quad$ Position angle of the drill bit within $0 \sim t$, the position change caused by the rotation of the drill bit, degree;

$\theta_{0} \quad$ Extreme position angle of the origin $\mathrm{O}^{\prime}$ of the moving coordinate system, degree;

$Z_{\mathrm{O}^{\prime}} \quad$ Vertical height of the moving coordinate origin $\mathrm{O}^{\prime}, \mathrm{mm}$;

$\delta \quad$ Front inclination angle of PDC cutter, degree;

$\eta \quad$ Lateral rotation angle of PDC cutter, degree;

\footnotetext{
* Corresponding author: kongcy@mail.xhu.edu.cn
} 
$\gamma \quad$ Angle between the baseline of the PDC tooth and the axis of the drill bit, degree;

$\sigma_{0} \quad$ Uniaxial compressive strength of limestone, and $\sigma_{0}=124 \mathrm{MPa}$;

$\sigma$

Uniaxial compressive strength of any rock, MPa.

\section{Introduction}

The main drill bits currently used in drilling engineering are PDC bits and tri-cone bits. The single-cone bit is a cutting type drill bit between the tri-cone bit and the Polycrystalline Diamond Compact (PDC) bit [1], and the cutting teeth on the cone crush the rock by rolling, scraping, and twisting. With its unique rock-breaking method and high ROP (Rate Of Penetration), it has won the favor of the drilling industry and has become the preferred drill bit for slim hole sidetracking and deep well drilling [2-6]. Although the single-cone bit is a good choice for slim hole drilling because of its good formation adaptability, strong guiding ability and easy to be small-sized [1, 7], according to the field application tracking investigation and statistical analysis, the single-cone bit also has a fatal weakness, that is, the wear resistance of the cutters is seriously insufficient $[1,8,9]$. The spherical single-cone bits currently used in the oil field (Fig. 1) all use cemented carbide inserts (such as cone button teeth, wedge teeth, etc.), which can only be used in soft formations; For hard formations with high abrasiveness, the early wear is severe and the life span is short $[10,11]$. This is because the single-cone bit will produce relatively large slip at the bottom of the well when it is working (Fig. 2), resulting in severe wear of the carbide cutting teeth. Therefore, the wear resistance of the cutting teeth will directly determine the working life of the single-cone bit. Once the cutters are dull, the drilling speed will decrease sharply. The main reason why the single-cone bit is less and less used is that the teeth are not wear-resistant, which leads to the ROP decline and short service life of the bit. It is of great practical significance and development prospect to research and design singlecone bits with strong abrasion resistance and wider lithological adaptability $[12,13]$.

Ma [14] founded the geometry and kinematics of modern roller cone bits. Wang et al. [15] and others [16] designed a special-shaped single-cone bit to increase the working life of the bit, but the special-shaped single-cone bit is not a fullhole drill, and the rock-breaking efficiency is still not high. Li [17] researched and designed a new type of impact press-in single-cone bit. After field application, it was found that the bit was worn seriously. Yu and Ding [18], Yu [19] and Deng et al. [20] studied the geometry, kinematics, and dynamics of the spherical single-cone bit, and discussed the design method of the tooth surface structure of the singlecone bit. $\mathrm{Yu}$ et al. [7] studied the influence of different geometric parameters and motion parameters for spherical single-cone bits on rock-breaking. However, many singlecone bit researchers have not conducted in-depth and detailed studies on the acceleration of PDC cutting teeth for the special motion trajectory of single-cone bits.

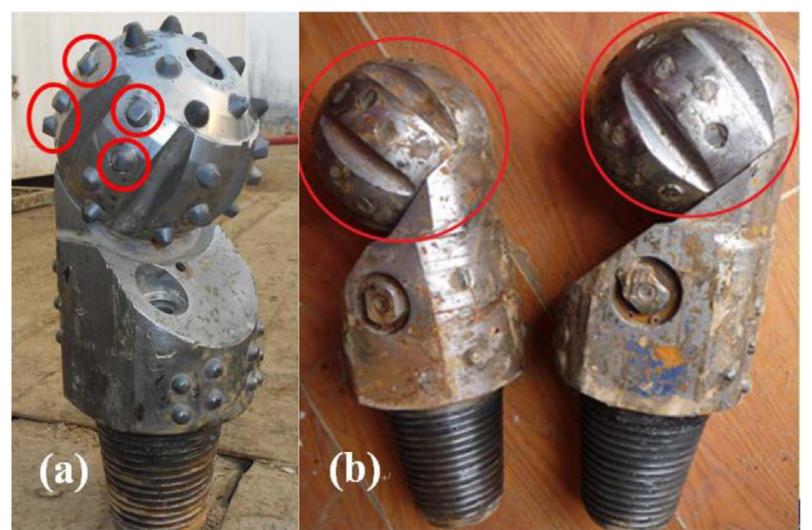

Fig. 1. Failed single-cone bit (a) worn cutting teeth (b) broken cutting teeth.

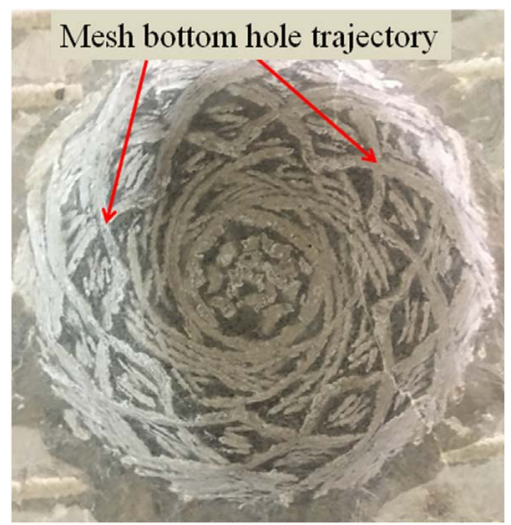

Fig. 2. Bottom hole pattern of single-cone bit.

In recent years, researchers have done a lot of research on bit technology. New bit technology is emerging, especially the improvement of bit performance brought by new bit structures. Baker Hughes Company has developed a new hybrid bit product by combining fixed PDC and unfixed cone. The special structure enables the bit to achieve good drilling results in some special formations and drilling requirements [21-25]. Smith bits of Schlumberger has successively launched $360^{\circ}$ rotary PDC bit $[26,27]$ and conical diamond element Bits [28-30]. These two kinds of bit have good performance in some special difficult to drill formation. Chen et al. proposed a new technology of single-cone bit, which is composed of fixed and unfixed [31]. The research team led by Professor Yang of Southwest Petroleum University proposed a diamond bit with unfixed cutting structure through structural innovation [32, 33], and many useful research results have been obtained [34-36]. Compared with the existing cone bit and PDC bit, the new bit has obvious advantages in rock breaking efficiency and service life. The bit is expected to form an efficient rock breaking tool in the near future. The structure of the bit has a decisive influence on the adaptability and performance of the bit. With the structural innovation, new research on new drill bits and new tools will have new breakthroughs [37]. Sometimes, the new bit structure can 

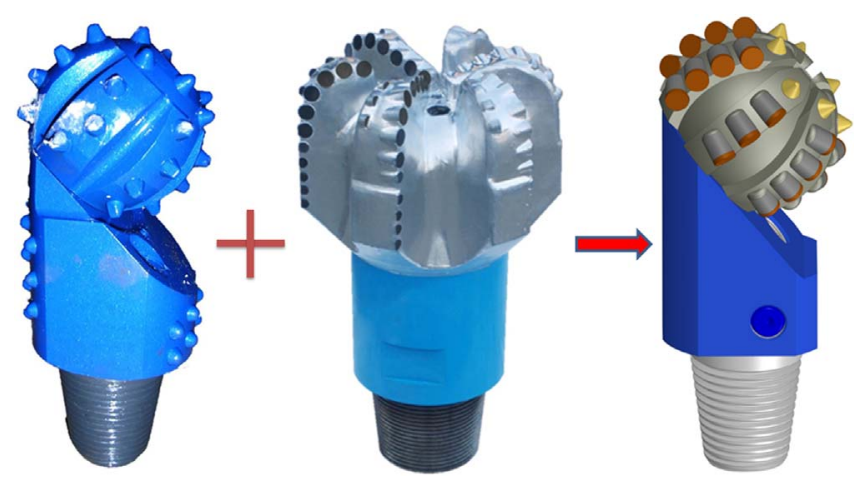

Fig. 3. Spherical single-cone PDC compound bit.

play a role of surprise and drive the development of drilling technology.

In order to overcome the shortcomings of the prior art (Fig. 1), improve the wear resistance of the single-cone bit and prolong the service life of the bit, based on an in-depth analysis of the structural characteristics and working principles of the single-cone bit, this paper adopts the design concept of the spherical single-cone bit + PDC bit and the principle that the PDC cutting teeth work slowly and alternately on the cone, with the design concept of spherical single-cone PDC compound bit proposed (Fig. 3). In order to make this new type of bit better serve the needs of oil drilling production, we need to conduct an in-depth study on the kinematics and related parameters for the PDC teeth on the single-cone bit. However, due to the changes in the tooth profile characteristics and tooth arrangement method for the new drill bit, the characteristic points on the PDC cutting tooth edge can no longer be simplified to any point on the cone sphere. Moreover, PDC teeth have cutting angles such as front inclination angle and lateral rotation angles during the rock-breaking process. It is necessary to re-establish the kinematics equations of the cutting teeth of the spherical single-cone PDC compound bit to thoroughly grasp the acceleration characteristics of the new type of bit, which provides basic support and reference for the dynamic research, subsequent design, development and application of this kind of bit.

\section{Establishment coordinate system}

As shown in Figure 4, when the spherical single-cone PDC compound bit is working, the movement of the cone includes the revolution of the bit body and cone around the center line of the bit, the movement along the direction of the center line of the bit, and the rotation of the cone around the cone axis. Any studies on the basic motions of cutters on cone shall be based on deep understanding of the features of bit in the coordinate system, basic plane and structure.

\subsection{Static cylindrical coordinate system}

Use the central axis of a single-cone bit as the coordinate axis $\mathrm{OZ}$ to establish a static/fixed cylindrical coordinate

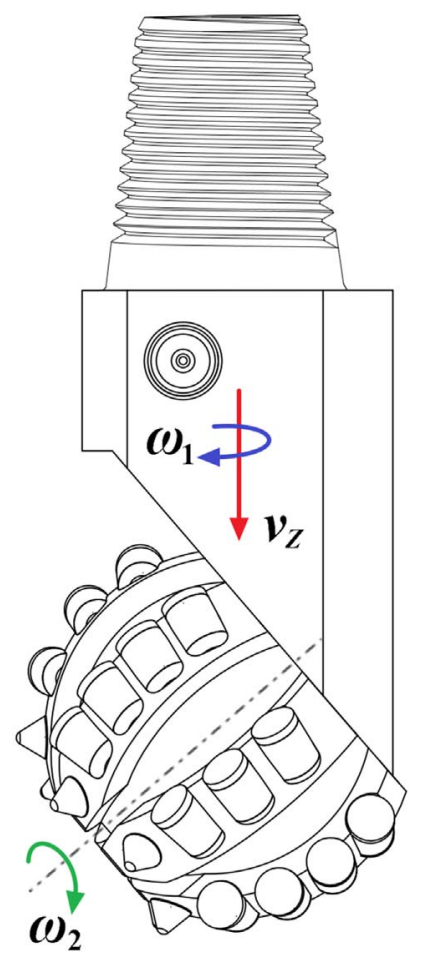

Fig. 4. The motion of spherical single-cone PDC compound bit.

system (static coordinate system) [20], set the polar axis on a horizontal reference plane and in a certain direction. Thereafter, a point $\mathrm{Q}$ within the space can be represented by $\mathrm{Q}(\rho, \theta, Z)$, as shown in Figure 5 .

\subsection{Dynamic cylindrical coordinate system}

Set up a dynamic cylindrical coordinate system for a singlecone [19], with the origin $\mathrm{O}^{\prime}$ set at the bottom center point of cone, the vertical axis $\mathrm{O}^{\prime} \mathrm{H}^{\prime}$ coinciding with the axis of cone, and polar axes $\mathrm{O}^{\prime} \mathrm{X}^{\prime}$ and $\mathrm{O}^{\prime} \mathrm{H}^{\prime}$ perpendicular with each other. The plane defined by $\mathrm{H}^{\prime} \mathrm{O}^{\prime} \mathrm{X}^{\prime}$ is called as a polar axis plane of cone.

Figure 6 shows the projection relationships of a complex cylindrical coordinate system, including: (a) view from direction $\mathrm{A}$ for the back cone plane of cone; (b) front view of single-cone; and (c) top view in addition to (b). Figure 6 indicates the parameters for bit structure as $(L, R, \beta)$, parameters for bit and cone positions as $\left(\theta_{0}, Z_{\mathrm{O}^{\prime}}, \alpha_{0}\right)$, parameters for PDC cutter's position on cone as $\left(h_{\mathrm{C}}, r_{\mathrm{C}}\right.$, $\gamma, \delta, \eta)$, and parameters of point Q's position on PDC cutter blade profile as $\left(r_{\mathrm{Q}}, \varphi\right)$.

Set up four rectangular coordinate systems for PDC cutters and respectively from the center points of four cutters [38]. Set up a coordinate system $\mathrm{O}_{1} \mathrm{X}_{1} \mathrm{Y}_{1} \mathrm{Z}_{1}$ for the position of $\mathrm{PDC}$ cutters, to make $\mathrm{O}_{1} \mathrm{Z}_{1} / / \mathrm{OZ}$ and pointing to the same direction as $\mathrm{OZ}$, and $\mathrm{O}_{1} \mathrm{X}_{1}$ in a horizontal direction and perpendicular to OZ. Rotate $\mathrm{O}_{1} \mathrm{X}_{1} \mathrm{Y}_{1} \mathrm{Z}_{1}$ around $\mathrm{O}_{1} \mathrm{Y}_{1}$ by an angle $\gamma$ (the included angle between the reference line of cutter and the axis of bit) in the clockwise direction to obtain a coordinate system $\mathrm{O}_{1} \mathrm{X}_{2} \mathrm{Y}_{2} \mathrm{Z}_{2}$, to make $\mathrm{O}_{1} \mathrm{X}_{2}$ collinear with the reference line of cutter and pointing to the 


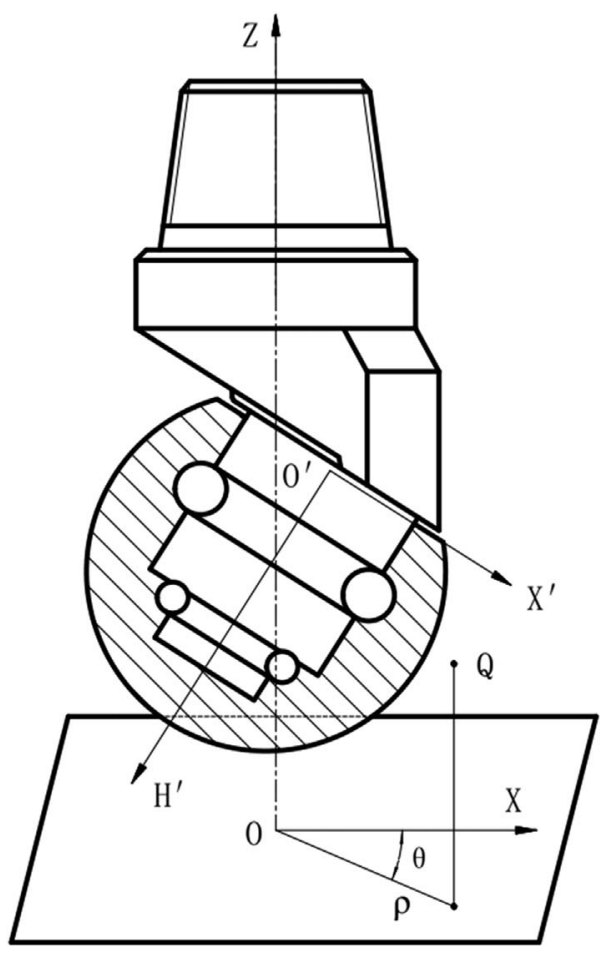

Fig. 5. Cylindrical coordinate system for bit.

external of bit. Rotate $\mathrm{O}_{1} \mathrm{X}_{2} \mathrm{Y}_{2} \mathrm{Z}_{2}$ around $\mathrm{O}_{1} \mathrm{X}_{2}$ by $\eta$ in the clockwise direction to obtain a coordinate system $\mathrm{O}_{1} \mathrm{X}_{3} \mathrm{Y}_{3} \mathrm{Z}_{3}$, to make $\mathrm{O}_{1} \mathrm{X}_{3}$ collinear with the reference line of cutter and pointing to the direction against from the center line of bit (coinciding with $\mathrm{O}_{1} \mathrm{X}_{3}$ ). Rotate $\mathrm{O}_{1} \mathrm{X}_{3} \mathrm{Y}_{3} \mathrm{Z}_{3}$ around $\mathrm{O}_{1} \mathrm{Z}_{3}$ by $\delta$ in the counterclockwise direction to obtain a coordinate system $\mathrm{O}_{1} \mathrm{X}_{4} \mathrm{Y}_{4} \mathrm{Z}_{4}$, to make $\mathrm{O}_{1} \mathrm{Z}_{4}$ perpendicular to the directional reference line of PDC cutter (coinciding with $\mathrm{O}_{1} \mathrm{Z}_{3}$ ).

In consideration of expressing all geometrical features of a cutter, such as points, lines and planes, define the parameter equations for the blade curves of the cutter as follows:

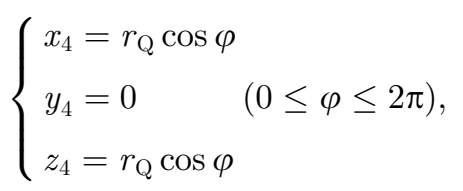

According to the principles for transformation of rectangular coordinate system, obtain the equations for the position coordinates for the blade profile of PDC cutter as follows:

$$
\left\{\begin{array}{c}
x_{4}=r_{\mathrm{Q}} \cos \varphi(\cos \delta \cos \gamma+\sin \delta \sin \eta \sin \gamma) \\
\quad-r_{\mathrm{Q}} \sin \varphi \cos \eta \sin \gamma \\
y_{1}=r_{\mathrm{Q}} \cos \varphi \sin \delta \cos \eta+r_{\mathrm{Q}} \sin \varphi \sin \eta \\
z_{1}=r_{\mathrm{Q}} \cos \varphi(\cos \delta \sin \gamma+\sin \delta \sin \eta \sin \gamma) \\
\quad+r_{\mathrm{Q}} \sin \varphi \cos \eta \sin \gamma
\end{array}\right.
$$

\section{Geometrical equations for describing motion of PDC cutters}

During operation, the motion of a single-cone bit consists of rotation and displacement, which are for the convenience of study analyzed in separation before combination of them.

\subsection{Rotation of cone}

\subsubsection{Relative rotation of cone around cone shaft}

Assume that the bit does not rotate, and the cone rotates around the cone shaft. Define the center point on a surface of PDC cutter as the characteristic point $\mathrm{C}(\rho, \theta, Z)$ and the initial position as $\alpha_{0}$. After a time lapse $t$, point $C$ moves to point $\mathrm{C}^{\prime}$ and arrives at a position angle $\alpha_{0}+\alpha$. Each view in Figure 6 includes the point $\mathrm{C}^{\prime}$ and its projection.

The true length is indicated as the distance between $\mathrm{O}$ and $\mathrm{C}^{\prime}$ to represent the radius vector of point $\mathrm{C}^{\prime}$ in the top view. $\mathrm{OC}^{\prime}$ constitutes the oblique side of the right triangle $\mathrm{ON}^{\prime} \mathrm{C}^{\prime}$, of which the right angle sides $\mathrm{ON}^{\prime}$ and $\mathrm{N}^{\prime} \mathrm{C}^{\prime}$ are as follows:

$$
\begin{aligned}
\overline{\mathrm{ON}^{\prime}} & =\overline{\mathrm{OM}}+\overline{\mathrm{MN}^{\prime}} \\
& =\left(L-h_{\mathrm{C}}\right) \cos \beta+r_{\mathrm{C}} \cos \left(\alpha_{0}+\alpha\right) \sin \beta,
\end{aligned}
$$

$$
\overline{\mathrm{N}^{\prime} \mathrm{C}^{\prime}}=r_{\mathrm{C}} \sin \left(\alpha_{0}+\alpha\right)
$$

wherein:

$$
r_{\mathrm{C}}=\sqrt{R^{2}-\left(L-h_{\mathrm{C}}\right)^{2}} .
$$

Subject to the time lapse $t$, calculate the radius vector $\rho_{\mathrm{Q}}$ of a point $\mathrm{Q}$ on the blade profile of cutter can be expressed as:

$$
\text { see equation (6) bottom of the page }
$$

\subsubsection{Rotation of cone and cone shaft around the center axis of bit}

Under the assumption that only the bit rotates, and the cone doesn't rotate around the cone shaft, point $\mathrm{C}^{\prime}$ conducts fixed-axis rotation around the center axis of bit, and, after the time lapse $t$, point $\mathrm{C}^{\prime}$ moves to point $\mathrm{C}^{\prime \prime}$ after travelling over the angle $\theta$, as shown in Figure 6 . The true value is reflected in the top view for the polar angle $\theta_{\mathrm{C}^{\prime \prime}}$ of the characteristic point $\mathrm{C}^{\prime \prime}$, and $\theta_{\mathrm{C}^{\prime \prime}}$ is the sum of the polar angle of point $\mathrm{O}^{\prime}$ and $\angle \mathrm{N}^{\prime} \mathrm{OC}^{\prime \prime}$, wherein:

$$
\angle \mathrm{N}^{\prime} \mathrm{OC}^{\prime \prime}=\theta-\varsigma,
$$

$$
\begin{aligned}
\varsigma & =\arctan \frac{\overline{\mathrm{N}^{\prime} \mathrm{C}^{\prime}}}{\overline{\mathrm{ON}^{\prime}}} \\
& =\arctan \frac{r_{\mathrm{C}} \sin \left(\alpha_{0}+\alpha\right)}{\left(L-h_{\mathrm{C}}\right) \cos \beta+r_{\mathrm{C}} \sin \beta \cos \left(\alpha_{0}+\alpha\right)},
\end{aligned}
$$

$$
\rho_{\mathrm{Q}}=\sqrt{\left.\left[\left(L-h_{\mathrm{C}}\right) \cos \beta+r_{\mathrm{C}} \cos \left(\alpha_{0}+\alpha\right) \sin \beta+x_{1}\right]^{2}\right]+\left[r_{\mathrm{C}} \sin \left(\alpha_{0}+\alpha\right)+y_{1}\right]^{2}} .
$$


(c)

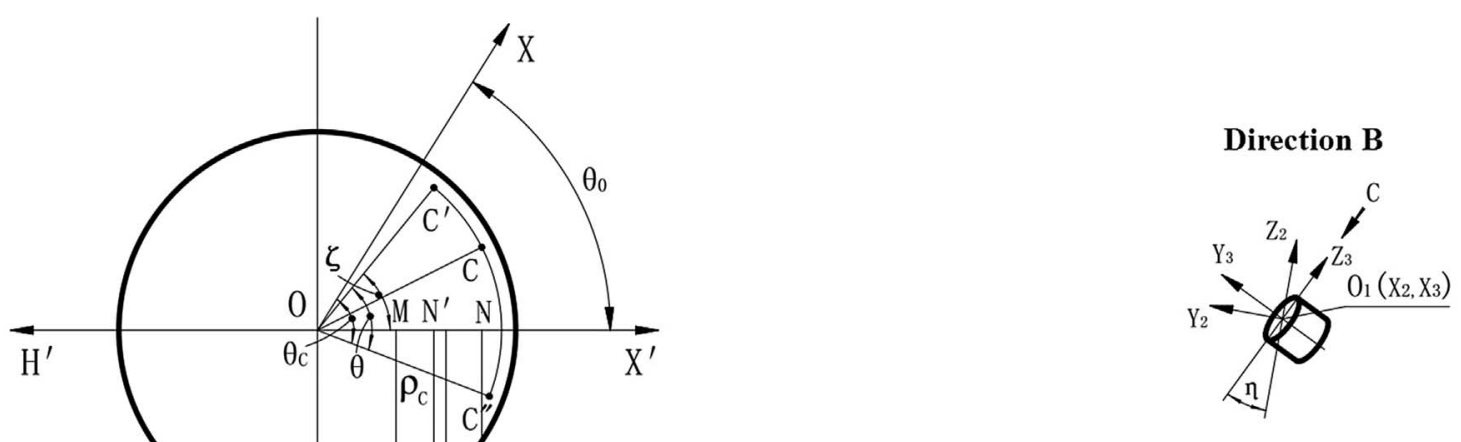

(a)

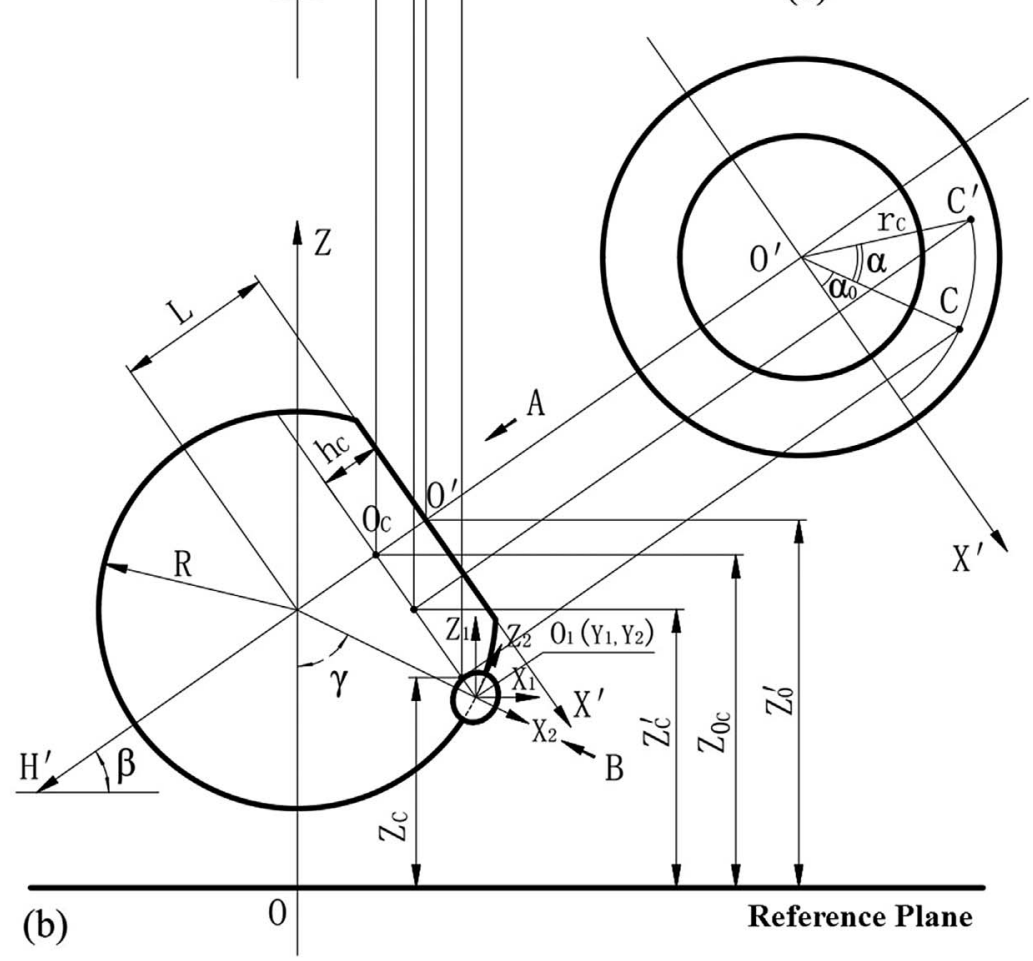

Direction C

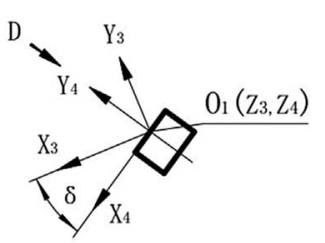

\section{Direction D}

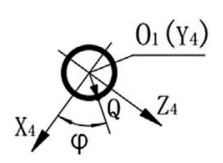

Fig. 6. Geometry of spherical single-cone PDC compound bit.

Accordingly, subject to the time lapse $t$, calculate the polar angle $\theta_{\mathrm{Q}}$ of a point $\mathrm{Q}$ on the blade profile of cutter can be expressed as:

$$
\begin{aligned}
\theta_{\mathrm{Q}}= & \theta_{0}+\theta \\
& -\arctan \frac{r_{\mathrm{C}} \sin \left(\alpha_{0}+\alpha\right)+y_{1}}{\left(L-h_{\mathrm{C}}\right) \cos \beta+r_{\mathrm{C}} \sin \beta \cos \left(\alpha_{0}+\alpha\right)+x_{1}}
\end{aligned}
$$

\subsection{Displacement of cone}

During operation, the cone moves along the center axis of bit in addition to rotation. The true length is reflected in Figure $6 \mathrm{~b}$ for the net vertical height $Z_{\mathrm{C}^{\prime}}$ of the characteristic point $\mathrm{C}$ after the time $t$. Accordingly, subject to the time lapse $t$, calculate the vertical height $Z_{\mathrm{Q}}$ of a point $\mathrm{Q}$ on the blade profile of cutter can be expressed as:

$$
Z_{\mathrm{Q}}=z_{\mathrm{O}}-r_{\mathrm{C}} \cos \left(\alpha_{0}+\alpha\right) \sin \beta-h_{\mathrm{C}} \sin \beta+z_{1} .
$$

Equations (6), (9) and (10) are kinematic geometric equations of the spherical single-cone PDC compound bit.

\section{Acceleration equation of PDC tooth on single-cone}

In order to facilitate the study of the acceleration of the PDC teeth on the cone, the rotation and movement of the cone are studied separately and combined. 
The angular velocity of the bit body is $\omega_{1}$, and the angular acceleration is $\varepsilon_{1}$.

$$
\varepsilon_{1}=\frac{\mathrm{d} \omega_{1}}{\mathrm{~d} t}=\frac{\mathrm{d}^{2} \theta}{\mathrm{d} t^{2}}
$$

The angular velocity of the cone around the cone axis is $\omega_{2}$, and its angular acceleration is $\varepsilon_{2}$.

$$
\varepsilon_{2}=\frac{\mathrm{d} \omega_{2}}{\mathrm{~d} t}=\frac{\mathrm{d}^{2} \alpha}{\mathrm{d} t^{2}}
$$

The up and down position of the bit body is $Z_{\mathrm{O}^{\prime}}$, and the acceleration is $a_{\mathrm{Z}}$

$$
a_{Z}=\frac{\mathrm{d}^{2} Z_{\mathrm{O}^{\prime}}}{\mathrm{d} t^{2}}
$$

$\varepsilon_{1}, \varepsilon_{2}$ and $a_{\mathrm{Z}}$ are all random variables, and through experimental measurements, it can be seen how their instantaneous real values change with time.

The acceleration of a characteristic point on a singlecone PDC tooth, especially the acceleration when the cutting tooth impacts with the bottom of the hole, is an important parameter for rock-breaking and cutting tooth strength. However, the actual measurement of the acceleration and dynamic load of the cutting teeth is very troublesome and cannot be implemented on a large scale. It is obviously very useful if the mathematical relationship between the acceleration of the PDC teeth of the singlecone bit and the above-mentioned measurable bit acceleration $\varepsilon_{1}, \varepsilon_{2}$ and $a_{Z}$ can be established.

In order to facilitate the study of the acceleration of the single-cone bit of the PDC tooth, the absolute movement of a certain characteristic point on the single-cone PDC tooth is regarded as the combination of the following three kinds of movements. That is, for the longitudinal implicated motion of point $\mathrm{Q}$, its position variable is $Z_{\mathrm{Q}}$, and its acceleration is $a_{Q_{Z}}$; for the tangentially implicated movement of point $\mathrm{Q}$, its position variable is the polar angle $\theta_{\mathrm{Q}}$, and the acceleration is $a_{\mathrm{Q} \tau}$; for the radial relative movement of point $\mathrm{Q}$, the position variable is the vector radius $\rho_{\mathrm{Q}}$, and the acceleration is $a_{\mathrm{Q} \rho}$; the three moving directions are $90^{\circ}$ with each other. Starting from the geometrical equation of motion of the single-cone bit, the acceleration equation of any point on the PDC tooth is established.

\section{(1) Relative acceleration $a_{r}$}

The acceleration caused by the radial movement is the relative acceleration, with the relative acceleration being the derivative of the radial velocity with respect to time $t$.

Let

$$
\begin{gathered}
A=\left(L-h_{\mathrm{C}}\right) \cos \beta, \\
B=r_{\mathrm{C}} \sin \beta,
\end{gathered}
$$

$\mathrm{C}=R_{\mathrm{Q}}(\cos \varphi \cos \delta \cos \gamma+\cos \varphi \sin \eta \sin \gamma-\sin \varphi \cos \eta \sin \gamma)$,

$$
\begin{gathered}
D=r_{\mathrm{Q}}(\cos \varphi \sin \delta \cos \eta+\sin \varphi \sin \eta) \\
\lambda_{\mathrm{C}_{\rho}}=\frac{1}{2 \rho_{\mathrm{Q}}} r_{\mathrm{C}} \cos ^{2} \beta \sin 2\left(\alpha_{0}+\alpha\right) \\
-\left(L-h_{\mathrm{C}}\right) \sin 2 \beta \sin \left(\alpha_{0}+\alpha\right) \\
\lambda_{\mathrm{C}_{\rho}}=\frac{1}{\rho_{\mathrm{Q}}}\left[\begin{array}{c}
\cos \left(\alpha_{0}+\alpha\right)(\cos \varphi \sin \delta \cos \eta \\
+\sin \varphi \sin \eta) \\
-\sin \beta \sin \left(\alpha_{0}+\alpha\right)(\cos \varphi \cos \delta \sin \gamma \\
+\cos \varphi \sin \varphi \sin \eta \cos \gamma-\sin \varphi \cos \eta \cos \gamma)
\end{array}\right] .
\end{gathered}
$$

Then there is

$$
\begin{aligned}
& a_{r}= \frac{\mathrm{d}^{2} \rho_{\mathrm{Q}}}{\mathrm{d} t^{2}}=\frac{1}{\rho_{\mathrm{Q}}}\left[\left(r_{\mathrm{C}}^{2}-B^{2}\right) \cos 2\left(\alpha_{0}+\alpha\right)-B \cos \left(\alpha_{0}+\alpha\right)\right. \\
&\left.(A+\mathrm{C})]-D r_{\mathrm{C}} \sin \left(\alpha_{0}+\alpha\right)\right] \omega_{2}^{2}+\frac{1}{\rho_{\mathrm{Q}}} \\
& \quad \times\left\{[ r _ { \mathrm { C } } - \operatorname { c o s } ^ { 2 } \beta \operatorname { s i n } ( \alpha _ { 0 } + \alpha ) + D ] r _ { \mathrm { C } } \operatorname { c o s } \left(\alpha_{0}\right.\right. \\
&\quad+\alpha)](A+C)\} \varepsilon_{2}-\frac{1}{\rho_{\mathrm{Q}}}\left(\lambda_{\mathrm{C}_{\rho}}+\lambda_{\mathrm{Q}_{\rho}} r_{Q}\right)^{2} r_{\mathrm{C}}^{2} \omega_{2}^{2}
\end{aligned}
$$

(2) Tangentially implicated acceleration $a_{e \tau}$ Let

$m=\frac{A \cos \left(\alpha_{0}+\alpha\right)+B+C \cos \left(\alpha_{0}+\alpha\right)+D \sin \beta \sin \left(\alpha_{0}+\alpha\right)}{\left[A+B \cos \left(\alpha_{0}+\alpha\right)+C\right]^{2}+\left[r_{\mathrm{C}} \sin \left(\alpha_{0}+\alpha\right)+D\right]^{2}}$,

$$
\begin{aligned}
& \frac{\mathrm{d} m}{\mathrm{~d} \alpha}=\frac{D \sin \beta \cos \left(\alpha_{0}+\alpha\right)-\sin \cos \left(\alpha_{0}+\alpha\right)(A+C)}{\rho_{\mathrm{Q}}^{2}} \\
& {\left[(A+C) \cos \left(\alpha_{0}+\alpha\right)+B+D \sin \beta \sin \left(\alpha_{0}+\alpha\right)\right]} \\
& \quad \times 2\left\{\left[A+B \cos \left(\alpha_{0}+\alpha\right)+C\right] r_{\mathrm{C}} \sin \beta \sin \left(\alpha_{0}+\alpha\right)\right. \\
& \\
& \quad \frac{\left.-\left[r_{\mathrm{C}} \sin \left(\alpha_{0}+\alpha\right)+D\right] r_{\mathrm{C}} \cos \left(\alpha_{0}+\alpha\right)\right\}}{\rho_{\mathrm{Q}}^{4}}
\end{aligned}
$$

Then there is

$$
a_{e \tau}=\rho_{\mathrm{Q}} \frac{\mathrm{d}^{2} \theta_{\mathrm{Q}}}{\mathrm{d} t^{2}}=\rho_{\mathrm{Q}}\left(\varepsilon_{1}-\frac{\mathrm{d} m}{\mathrm{~d} \alpha} r_{\mathrm{C}} \omega_{2}^{2}-m r_{\mathrm{C}} \varepsilon_{2}\right) .
$$

(3) Implicated centripetal acceleration $a_{e \rho}$

The radially implicated centripetal acceleration caused by the rotation of the drill bit is:

$$
a_{e \rho}=\rho_{\mathrm{Q}}\left(\frac{\mathrm{d} \theta_{\mathrm{Q}}}{\mathrm{d} t}\right)^{2}=\rho_{\mathrm{Q}}\left(\omega_{1}-m r_{\mathrm{C}} \omega_{2}\right)^{2} .
$$

(4) Longitudinal implicated acceleration $a_{e Z}$

$$
\begin{aligned}
a_{e Z}= & \frac{\mathrm{d}^{2} Z_{\mathrm{Q}}}{\mathrm{d} t^{2}} \\
= & a_{Z}+r_{\mathrm{C}} \cos \beta \cos \left(\alpha_{0}+\alpha\right) \omega_{2}^{2}+r_{\mathrm{C}} \\
& \times \cos \beta \sin \left(\alpha_{0}+\alpha\right) \varepsilon_{2} .
\end{aligned}
$$


(5) Coriolis acceleration $a_{k}$

The Coriolis acceleration caused by the change in the direction of the relative speed caused by the implicated rotation and the change in the magnitude of the implicated speed caused by the relative speed, expressed by the vector $a_{k}$. By the definition of Coriolis acceleration, its magnitude is:

$$
\begin{aligned}
a_{k}= & 2 \frac{\mathrm{d} \rho_{\mathrm{Q}}}{\mathrm{d} t} \frac{\mathrm{d} \theta_{\mathrm{Q}}}{\mathrm{d} t} \\
& \times \sin \Psi 2\left(\lambda_{\mathrm{C} \rho}+\lambda_{\mathrm{Q} \rho} r_{\mathrm{Q}}\right) r_{\mathrm{C}} \omega_{2}\left(\omega_{1}-m r_{\mathrm{C}} \omega_{2}\right) .
\end{aligned}
$$

wherein, $\Psi$ is the angle between the relative speed and the angular velocity of the implicated rotation, $\Psi=90^{\circ}$; the direction of $a_{\mathrm{k}}$ is perpendicular to the plane defined by $\omega_{\mathrm{Q}}$ and $v_{\mathrm{Q} \rho}$, pointing to the tangential direction.

Thus, the radial acceleration $a_{\mathrm{Q} \rho}$, the tangential acceleration $a_{\mathrm{Q} \tau}$, and the longitudinal acceleration $a_{\mathrm{QZ}}$ at point $\mathrm{Q}$ on the cutting tooth are obtained:

\section{the radial acceleration $a_{\mathrm{Q} \rho}$}

$$
\begin{gathered}
a_{\mathrm{Q} \rho}=a_{r}+a_{e \rho}=\frac{1}{\rho_{\mathrm{Q}}}\left[\left(r_{\mathrm{C}}^{2}-B^{2}\right) \cos 2\left(\alpha_{0}+\alpha\right)\right. \\
\left.-B \cos \left(\alpha_{0}+\alpha\right)(A+C)-D r_{\mathrm{C}} \sin \left(\alpha_{0}+\alpha\right)\right] \omega_{2}^{2} \\
+\frac{1}{\rho_{\mathrm{Q}}}\left\{\left[r_{\mathrm{C}} \cos ^{2} \beta \sin \left(\alpha_{0}+\alpha\right)+D\right] r_{\mathrm{C}} \cos \left(\alpha_{0}+\alpha\right)\right. \\
\left.-B \sin \left(\alpha_{0}+\alpha\right)(A+C)\right\} \varepsilon_{2} \\
-\frac{1}{\rho_{\mathrm{Q}}}\left(\lambda_{\mathrm{C} \rho}+\lambda_{\mathrm{Q} \rho} r_{\mathrm{Q}}\right)^{2} r_{\mathrm{C}}^{2} \omega_{2}^{2}+\rho_{\mathrm{Q}}\left(\omega_{1}-m r_{\mathrm{C}} \omega_{2}\right)^{2},
\end{gathered}
$$

\section{the tangential acceleration $a_{\mathrm{Q} \tau}$}

$$
\begin{aligned}
a_{\mathrm{Q} \tau}= & a_{k}+a_{e \tau} \\
= & 2 r_{\mathrm{C}} \omega_{2}\left(\omega_{1}-m r_{\mathrm{C}} \omega_{2}\right)\left(\lambda_{\mathrm{C} \rho}+\lambda_{\mathrm{Q} \rho} r_{\mathrm{Q}}\right) \\
& +\rho_{\mathrm{Q}}\left(\varepsilon-\varepsilon_{1}-\frac{\mathrm{d} m}{\mathrm{~d} \alpha} r_{\mathrm{C}} \omega_{2}^{2}-m r_{\mathrm{C}} \varepsilon_{2}\right),
\end{aligned}
$$

\section{the longitudinal acceleration $a_{\mathrm{QZ}}$}

$$
\begin{aligned}
a_{\mathrm{QZ}}= & a_{e Z} \\
= & a_{Z}+r_{\mathrm{C}} \cos \beta \cos \left(\alpha_{0}+\alpha\right) \omega_{2}^{2}+r_{\mathrm{C}} \\
& \times \cos \beta \sin \left(\alpha_{0}+\alpha\right) \varepsilon_{2},
\end{aligned}
$$

so, the absolute acceleration $a_{\mathrm{Q}}$ at point $\mathrm{Q}$ on the cutting tooth is:

$$
a_{\mathrm{Q}}=\sqrt{a_{\mathrm{Q} \rho}^{2}+a_{\mathrm{Q} \tau}^{2}+a_{\mathrm{Q} Z}^{2}}
$$

\section{Calculation examples and analysis}

\subsection{Relationship between the transmission ratio of the single-cone bit and the rock}

The relationship between the roller speed and the bit rotation speed is the transmission ratio. Through analyzing and summarizing the experimental data of the transmission ratio of the spherical single-cone bit in the literature [39], the empirical formula of the transmission ratio $i$ can be obtained.

$$
\begin{aligned}
i= & 0.26 \cos ^{2} \beta+\frac{\sigma-\sigma_{0}}{\sigma_{0}}(0.318 \cos \beta-0.06)+1.888 \\
& \times \sin \beta-0.95 .
\end{aligned}
$$

Three common rocks are selected: sandstone $(\sigma=33.44$ $\mathrm{MPa})$, limestone $(\sigma=124 \mathrm{MPa})$ and granite $(\sigma=236$ $\mathrm{MPa}$ ). According to the empirical formula of transmission ratio, the change trend of transmission ratio $i$ of single-cone bit in three kinds of rocks with shaft inclination angle $\beta$ can be obtained, as shown in Figure 7. It can be seen from the curve in the figure that as $\beta$ increases, the bit transmission ratio $i$ also gradually increases, and that the transmission ratio of a single-cone bit in granite is higher than that in sandstone, that is, the harder the rock, the higher the transmission ratio of the bit. Of course, the transmission ratio of a single-cone bit is not only related to the shaft inclination angle and rock characteristics, but also to the bit tooth surface structure. However, according to previous experimental studies, it can be known that the shaft inclination angle and rock characteristics are the main factors affecting the transmission ratio, so the empirical formula for transmission ratio has certain applicability to single-cone bits. The influence of the new tooth surface structure on the transmission ratio of the spherical single-cone PDC compound bit needs to be supplemented and improved in the follow-up experimental research.

\subsection{Analysis of factors affecting acceleration}

In order to further clarify the influence of each parameter of the PDC tooth single-cone bit on the acceleration, the acceleration of the PDC tooth single-cone bit is quantitatively analyzed and studied in combination with some parameters given in reference [20], with the given parameters being $L=30 \mathrm{~mm}, R=50 \mathrm{~mm}, h_{\mathrm{C}}=40 \mathrm{~mm}, \beta=60^{\circ}, \alpha=30^{\circ}$, $\eta=5^{\circ}, \delta=38^{\circ}, r_{\mathrm{Q}}=6.72 \mathrm{~mm}, \omega_{1}=60 \mathrm{r} / \mathrm{min}$, and $i=0.748$ (limestone). The diameter of the spherical single-cone PDC compound bit is $118 \mathrm{~mm}$. The front inclination angle $\delta$, the radius $r_{\mathrm{Q}}$ of the PDC tooth, the lateral rotation angle $\eta$, the shaft inclination angle $\beta$, the position height $h_{\mathrm{C}}$ of the PDC tooth, and the rock strength are selected as independent variables. The above basic parameters are substituted into equations (27)-(30) for numerical calculation.

The acceleration simulation calculation result of the spherical single-cone PDC compound bit is shown in Figures $8-12$. It can be seen from Figure 8 that the tangential acceleration $a_{\mathrm{Q} \tau}$ and the absolute acceleration $a_{\mathrm{Q}}$ increase with the increase of the front inclination angle $\delta$, and that the radial acceleration $a_{\mathrm{Q} \rho}$ decreases slightly with the increase of $\delta$; the longitudinal acceleration $a_{\mathrm{Q} Z}$ has nothing to do with $\delta$. It can be seen from Figure 9 that $a_{\mathrm{Q} \rho}, a_{\mathrm{Q} \tau}$ and $a_{\mathrm{Q}}$ all increase slightly with the increase of the radius $r_{\mathrm{Q}}$ of the PDC tooth, but the amplitude of the change is small; $a_{\mathrm{QZ}}$ has nothing to do with $r_{\mathrm{Q}}$. It can be seen from Figure 10 that $a_{\mathrm{Q} \rho}, a_{\mathrm{Q} \tau}$ and $a_{\mathrm{Q}}$ all decrease slowly with the increase of the lateral rotation angle $\eta ; a_{\mathrm{Q} Z}$ has nothing to do with $\eta$. It can be seen from Figure 11 that the shaft inclination angle $\beta$ 


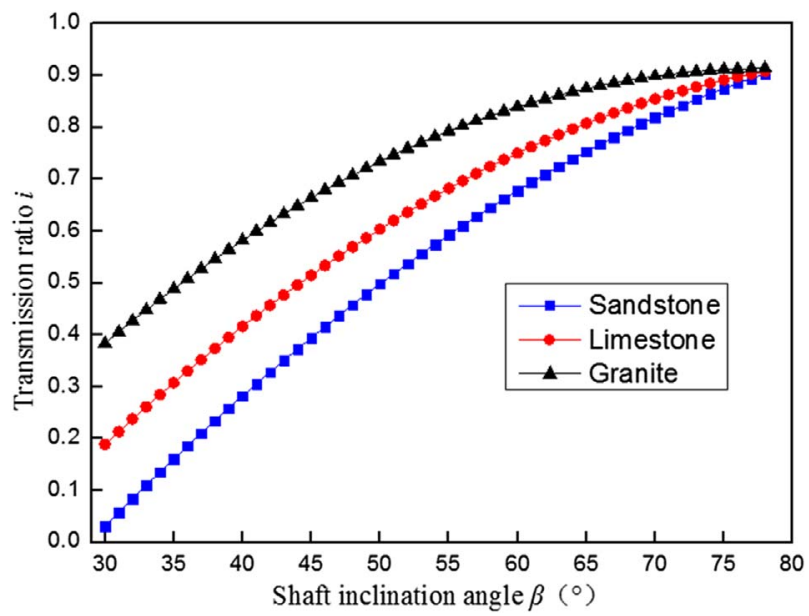

Fig. 7. Change of transmission ratio at shaft inclination angle.

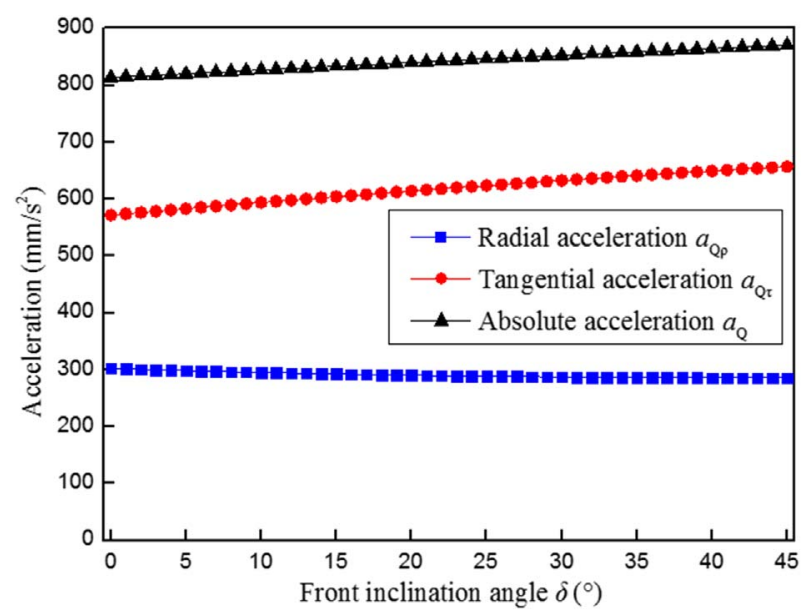

Fig. 8. Effect of front inclination angle on acceleration.

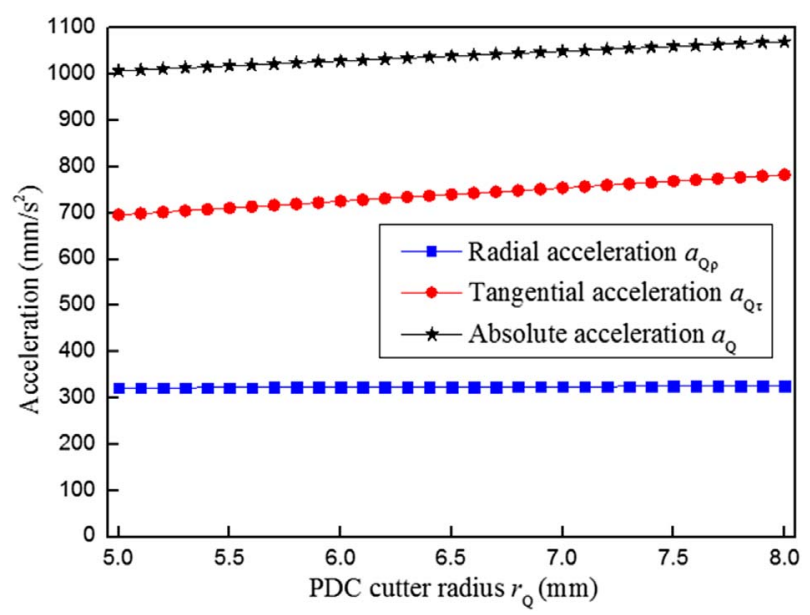

Fig. 9. Effect of PDC cutter radius on acceleration.

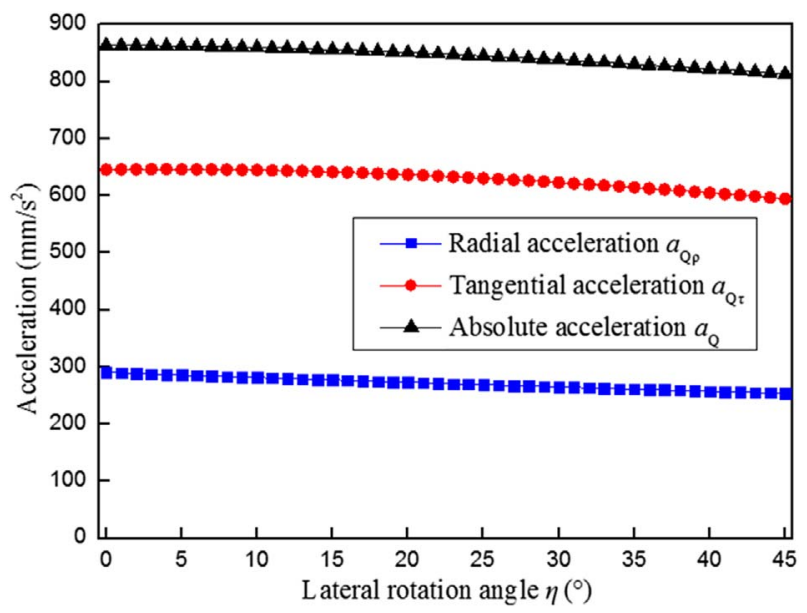

Fig. 10. Effect of lateral rotation angle on acceleration.

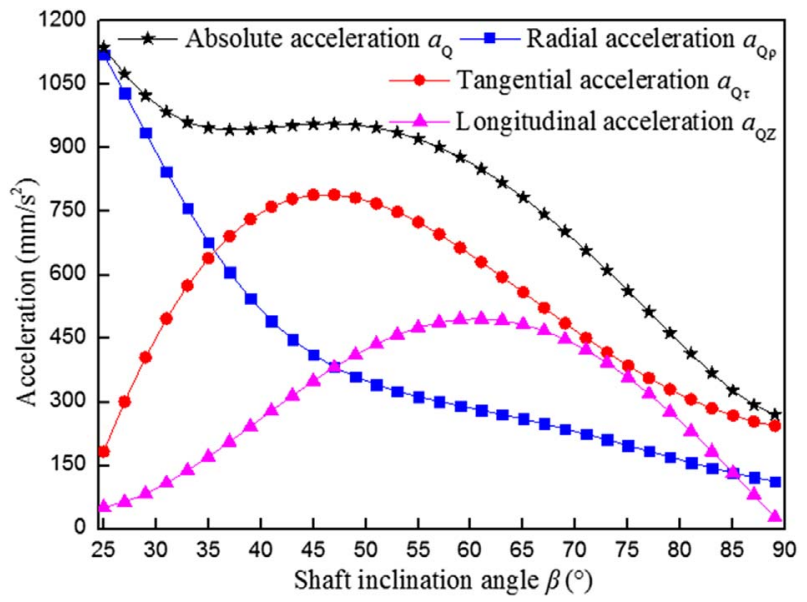

Fig. 11. Effect of shaft inclination angle on acceleration.

has a relatively large impact on acceleration, where $a_{\mathrm{Q} \rho}$ decreases as $\beta$ increases, and that both $a_{\mathrm{Q} \tau}$ and $a_{\mathrm{Q} Z}$ first increase and then decrease with $\beta$ increase; as $\beta$ increases, $a_{\mathrm{Q}}$ first decreases, then remains unchanged, and finally decreases. It can be seen from Figure 12 that the position height $h_{\mathrm{C}}$ of the PDC tooth also has a relatively large impact on the acceleration, and between 0 and $65 \mathrm{~mm}$, $a_{\mathrm{Q} \rho}, a_{\mathrm{Q} \tau}$ and $a_{\mathrm{Q}}$ all increase as $h_{\mathrm{C}}$ increases; between 65 and $80 \mathrm{~mm}, a_{\mathrm{Q} \tau}$ decreases sharply with the increase of $h_{\mathrm{C}}$ and approaches zero, $a_{\mathrm{Q} \rho}$ and $a_{\mathrm{Q}}$ increase greatly with the increase of $h_{\mathrm{C}}$, and decrease sharply when they are close to the top of the cone; $a_{\mathrm{Q} Z}$ has nothing to do with $h_{\mathrm{C}}$.

Sandstone $(\sigma=33.44 \mathrm{MPa})$, limestone $(\sigma=124 \mathrm{MPa})$ and granite ( $\sigma=236 \mathrm{MPa})$, and combine equation (31) are selected to quantitatively analyze and calculate the absolute acceleration of the PDC teeth of the single-cone bit, with the results shown in Figures 13-15. The analysis results show that because rock formations of different hardness will cause changes in the bit transmission ratio, the 


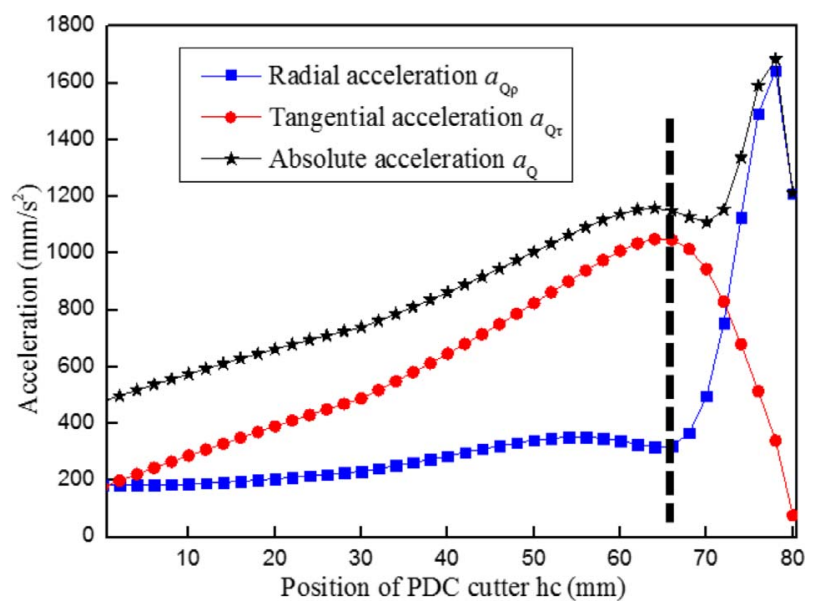

Fig. 12. Effect of PDC cutter position on acceleration.

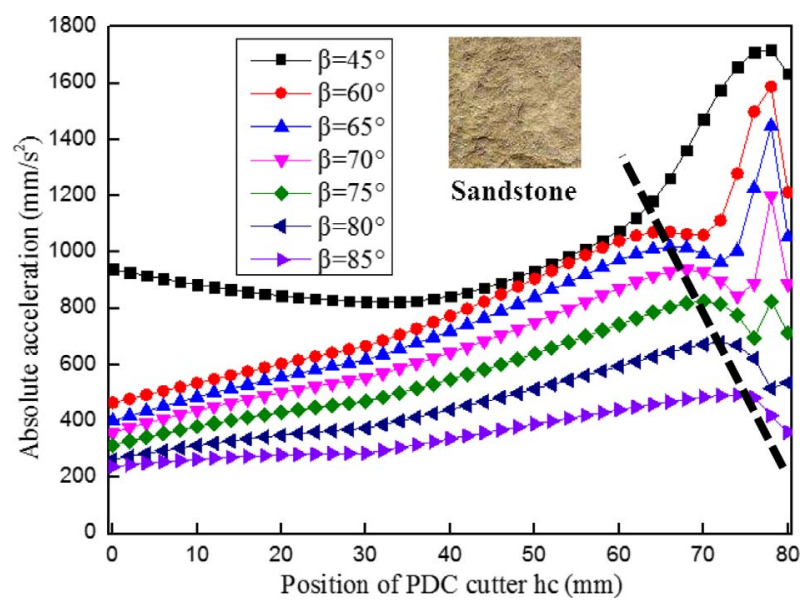

Fig. 13. Relationship between the absolute acceleration and $h_{\mathrm{C}}$ (sandstone).

rock formations also have a certain influence on the acceleration of the cutting teeth, and that the acceleration of the cutting teeth in sandstone is slightly lower than that in granite; the absolute acceleration of the cutting teeth at most positions on the cone in different rock formations tends to be gentle with the increase of $\beta$. However, near the top of the cone, the absolute acceleration of the cutting teeth will fluctuate violently and cause severe wear of the cutting teeth; the greater $\beta$, the closer the absolute acceleration fluctuation position is to the top of the cone, and the smaller the fluctuation amplitude. Therefore, the tooth placement in the area to the right of the dotted line in Figures 13-15 require special attention from single-cone bit researchers. At the same time, the larger $\beta$, the smaller the absolute acceleration, indicating that the inertial force of the drill bit is smaller and that it is more beneficial to the strength of the PDC tooth; however, considering the wear of the roller bearing [40,41], the shaft inclination angle $\beta$ of the single-cone bit cannot be designed too large.

The bit design should try to achieve the goal of equal life, that is, the life of each component of the cone bit is

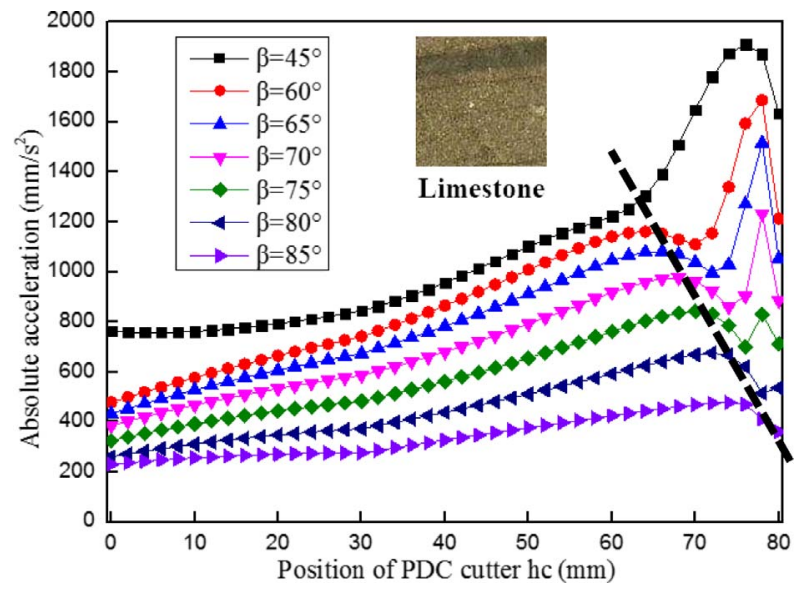

Fig. 14. Relationship between the absolute acceleration and $h_{\mathrm{C}}$ (limestone).

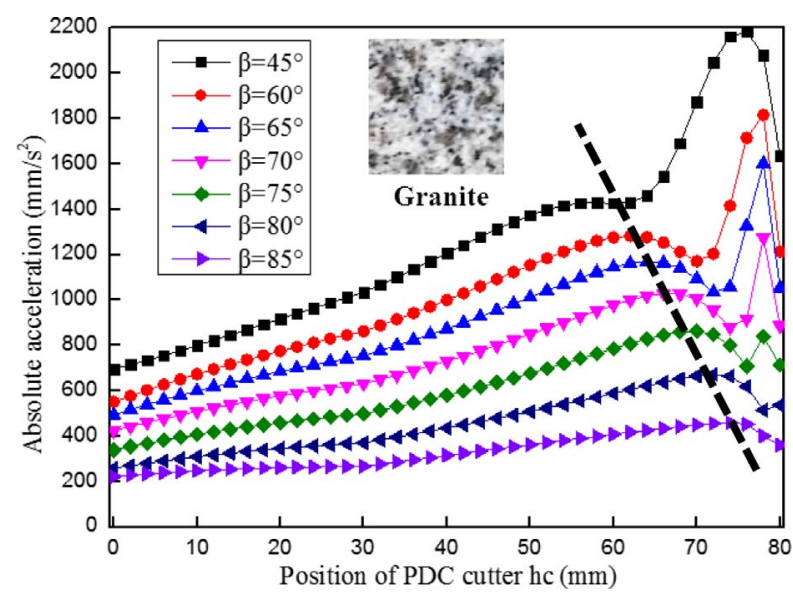

Fig. 15. Relationship between the absolute acceleration and $h_{\mathrm{C}}$ (granite).

almost the same. For a single-cone bit, it mainly means that the roller bearing and the bit cutting teeth reach the same life. Therefore, under the premise that the bearing life of the single-cone bit is allowed, the shaft inclination angle $\beta$ can be approached to $70^{\circ}$.

\subsection{Multi-factor composite analysis of acceleration}

According to Figures 13-15, it is known that among the various factors affecting the acceleration of the cutting teeth of the spherical single-cone PDC compound bit, the shaft inclination angle and the position height of the PDC teeth have the greatest impact on the acceleration. Therefore, in order to comprehensively investigate the influence trend of $\beta$ and $h_{\mathrm{C}}$ of the PDC tooth on the acceleration, $\beta$ and $h_{\mathrm{C}}$ are used as independent variables at the same time in analyzing and calculating the radial acceleration $a_{\mathrm{Q} \rho}$, tangential acceleration $a_{\mathrm{Q} \tau}$, longitudinal acceleration $a_{\mathrm{QZ}}$ and absolute acceleration $a_{\mathrm{Q}}$ in the limestone with these two independent variables, as shown in Figures 16-19. 


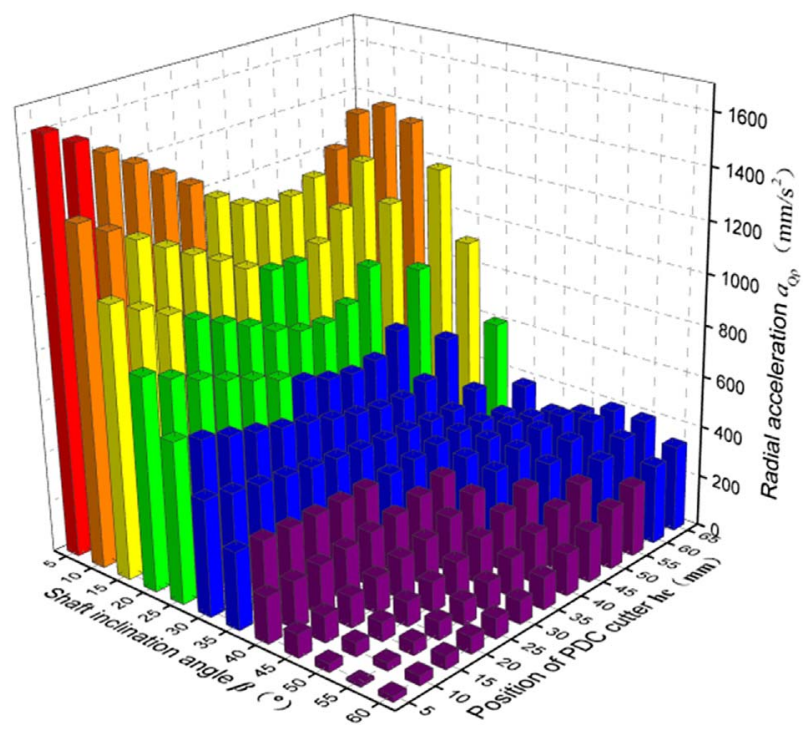

Fig. 16. Change of radial acceleration along with $h_{\mathrm{C}}$ and $\beta$.

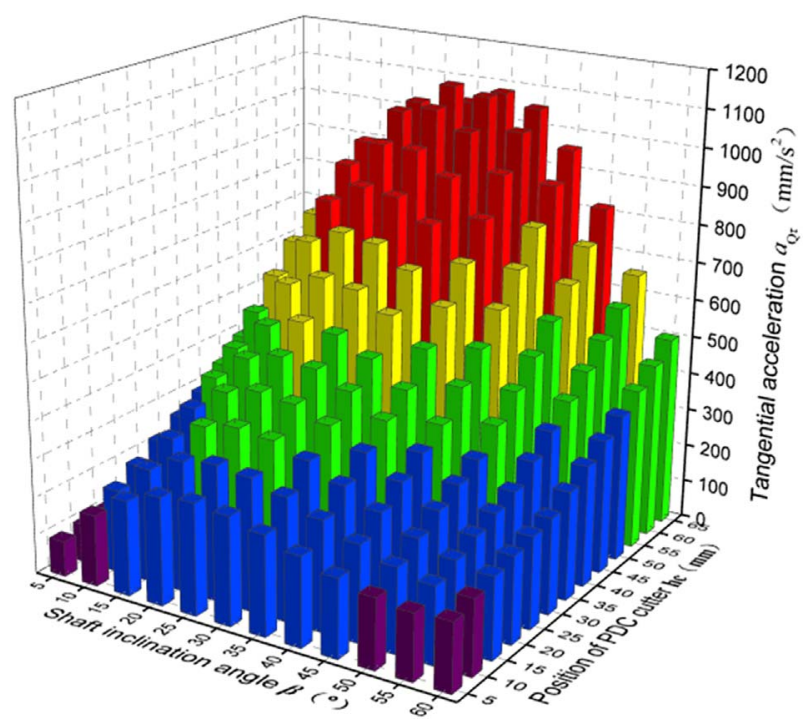

Fig. 17. Change of tangential acceleration along with $h_{\mathrm{C}}$ and $\beta$.

It can be seen from Figures 16-19 that when the position height $h_{\mathrm{C}}$ of the PDC teeth and the shaft inclination angle $\beta$ increase at the same time, the radial acceleration $a_{\mathrm{Q} \rho}$ first decreases and then tends to be gentle. When $\beta=40^{\circ} \sim 60^{\circ}$, the radial acceleration $a_{\mathrm{Q} \rho}$ change law tends to be stable as a whole, and slowly increases with the increase of $h_{\mathrm{C}}$. The tangential acceleration $a_{\mathrm{Q} \tau}$ first increases and then slowly decreases with the increase of $\beta$ and $h_{\mathrm{C}}$. When $\beta=30^{\circ} \sim 40^{\circ}$, the tangential acceleration $a_{\mathrm{Q} \tau}$ reaches the maximum value, and the maximum value is close to the top area of the cone. The longitudinal acceleration $a_{\mathrm{QZ}}$ first increases and then decreases with the increase of $\beta$ and $h_{\mathrm{C}}$. When $\beta=40^{\circ}$, the longitudinal acceleration $a_{\mathrm{QZ}}$ of the PDC teeth in the middle of the cone reaches the maximum. The absolute acceleration $a_{\mathrm{Q}}$ decreases first and then stabilizes with the increase of $\beta$

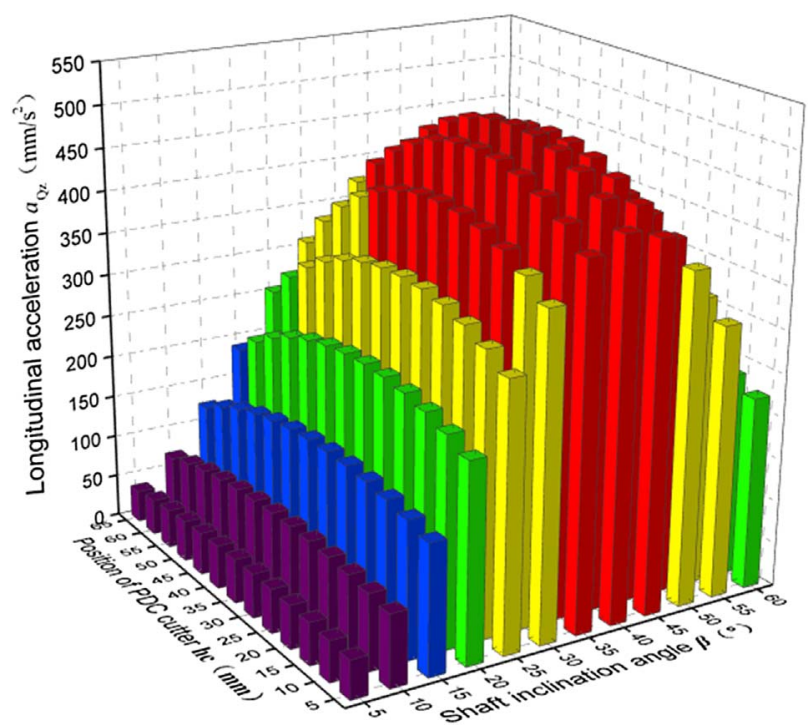

Fig. 18. Change of longitudinal acceleration along with $h_{\mathrm{C}}$ and $\beta$.

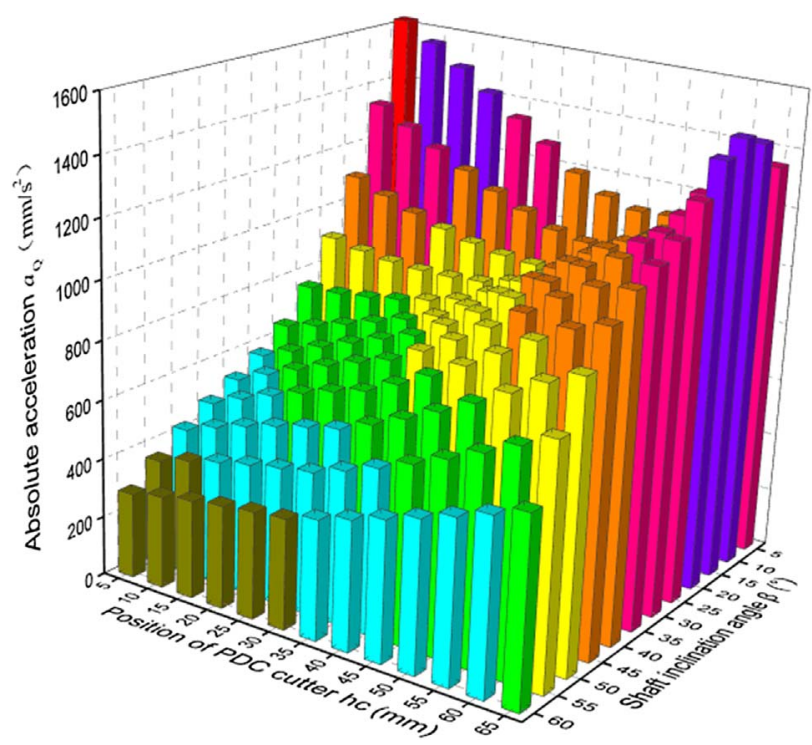

Fig. 19. Change of absolute acceleration along with $h_{\mathrm{C}}$ and $\beta$.

and $h_{\mathrm{C}}$. When $\beta$ and $h_{\mathrm{C}}$ take the minimum at the same time, the absolute acceleration $a_{\mathrm{Q}}$ reaches the maximum; when $\beta$ takes the maximum, the absolute acceleration $a_{\mathrm{Q}}$ of the PDC tooth at the end of the cone reaches the minimum.

In order to verify the theoretical analysis results of the acceleration of the spherical single-cone PDC compound bit in this paper, the nonlinear dynamical model is established to simulate the dynamic rock breaking process of the spherical single-cone PDC compound bit on basis of which the acceleration state of the bit element during the rock breaking process is simulated. It provides a theoretical basis for the application and design of the spherical singlecone PDC compound bit. 

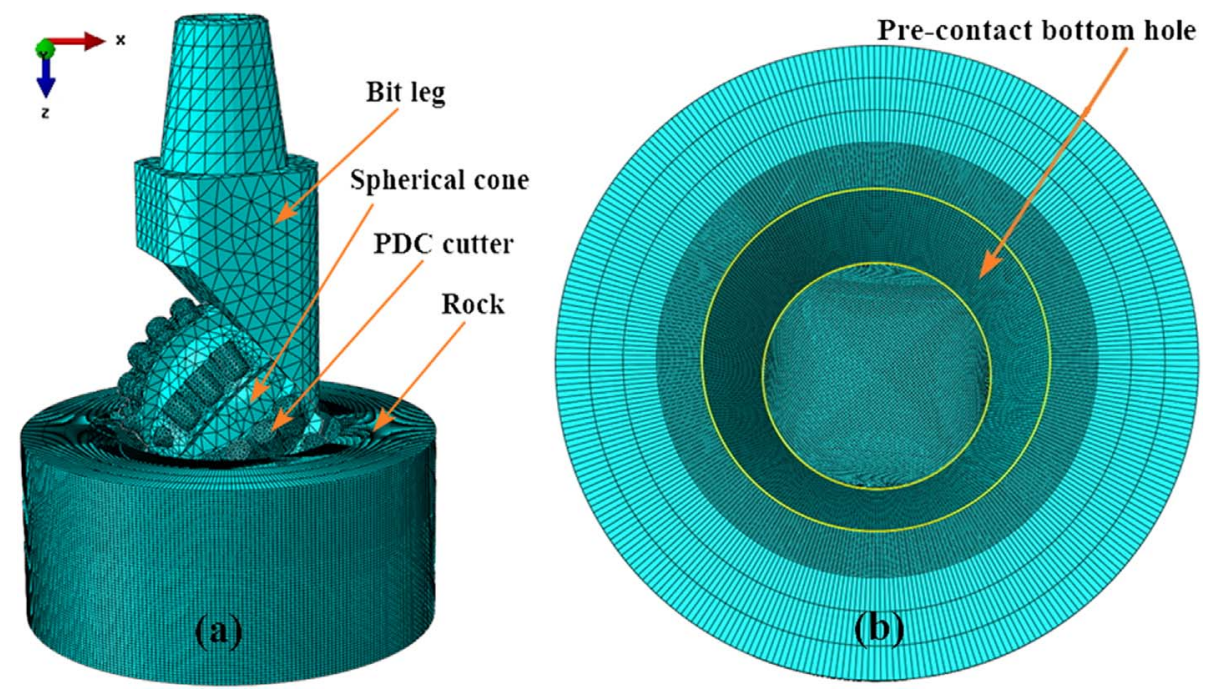

Fig. 20. Finite element model of the drill bit-rock system (a) Overall model, (b) Rock model.

\section{Rock-breaking simulation experiment}

In the actual drilling process, there are many factors that affect the rock-breaking of the drill bit. In the process of numerical simulation of the rock-breaking of the drill bit using the finite element method, it is impossible to consider the influence of all factors on the simulation results. The specific problems and research goals should be addressed. The simulation model is appropriately simplified and necessary assumptions are made. To facilitate the analysis the drilling process of the spherical single-cone PDC compound bit, the following assumptions are taken:

1. The palm and cone of the drill bit are regarded as rigid bodies.

2. The influences of temperature, confining pressure, and drilling fluid are neglected.

3. The bottom of the well is kept clean at all times, that is, the rock grid unit will be automatically deleted after failure, ignoring its impact on the subsequent cutting.

4. The rock is continuous isotropic medium, ignoring the effects of initial cracks and internal pressure.

5. The axis of the drill bit coincides with the axis of the borehole, ignoring the possible radial displacement of the drill bit.

\subsection{Finite-Element model of the drill bit-rock system}

The PDC bit exhibits highly nonlinear characteristics during the rock-breaking process, including geometric nonlinearity, material nonlinearity and contact nonlinearity. By adopting the finite element method, treat the spatial domain of the cutter-rock contacting system at time $t$ as $\Omega$, and the body force, boundary stress and Cauchy's stress respectively as $b, r, r_{\mathrm{C}}$ and $\sigma_{\mathrm{C}}$, then the contacting issue could be represented as [42, 43]:
Table 1. Mechanical parameters of each part of the drill bit.

\begin{tabular}{lccc}
\hline Parts of the bit & $\begin{array}{c}\text { Elastic } \\
\text { modulus/GPa }\end{array}$ & Poisson's ratio $\begin{array}{r}\text { Density/ } \\
\mathrm{kg} / \mathrm{m}^{3}\end{array}$ \\
\hline Cutter & 800 & 0.08 & 4100 \\
Cone & 218 & 0.30 & 7800 \\
Bit leg & 208 & 0.295 & 7800 \\
\hline \multicolumn{4}{c}{$\int_{\Omega} \sigma_{\mathrm{C}} \delta_{e} \mathrm{~d} \Omega-\int_{\Omega} b \delta_{u} \mathrm{~d} \Omega-\int_{\Gamma_{f}} r \delta_{e} \mathrm{~d} S-\int_{\Gamma_{\mathrm{c}}} r_{\mathrm{C}} \delta_{u} \mathrm{~d} S$} \\
& $+\int_{\Omega} \rho a_{1} \delta_{u} \mathrm{~d} \Omega=0$,
\end{tabular}

wherein, $\Gamma_{f}$ is the border for a given boundary force, $\Gamma_{\mathrm{c}}$ is the contact boundary, $\delta_{u}$ is the virtual displacement, $\delta_{e}$ is the virtual strain, $\rho$ is the density, $a_{1}$ represents the acceleration. By discretizing the spatial domain $\Omega$ with finite element method, one can obtain the following equation:

$$
\mathbf{M} \ddot{\mathbf{u}}=\mathbf{p}(t)+\mathbf{c}(u, \xi)-\mathbf{h}(u, \lambda),
$$

wherein, $\mathbf{M}$ is the mass matrix, $\ddot{v}$ is the acceleration vector, $t$ is the time variable, $\mathbf{p}$ is the external force vector, $\mathbf{c}$ is the contact force and friction force vector, $\mathbf{h}$ is the internal stress vector, $u$ is the object displacement, $\xi$ is the variable associated with contact surface characteristics, and $\lambda$ represents the variable associated with constitutive relation of materials.

Considering that a proper plastic constitutive model is the key of accurately simulating the yielding, hardening and damaging process, and that bottom-hole rock is a kind of granular material so that the rock element will be expanded when suffering shear force, Drucker-Prager model $[36,44]$ is adopted in this paper.

According to the above theory, combined with the bit structure designed in Figure 3, with the given structural parameters being $L=30 \mathrm{~mm}, R=50 \mathrm{~mm}, \beta=70^{\circ}$, 
Table 2. Mechanical parameters of rock material [33].

\begin{tabular}{lccccccc}
\hline Rock sample & $\begin{array}{c}\text { Elastic } \\
\text { modulus/GPa }\end{array}$ & $\begin{array}{c}\text { Poisson's } \\
\text { ratio }\end{array}$ & $\begin{array}{c}\text { Density/ } \\
\mathrm{kg} / \mathrm{m}^{3}\end{array}$ & $\begin{array}{c}\text { Compressive } \\
\text { strength/MPa }\end{array}$ & $\begin{array}{c}\text { Tensile } \\
\text { strength/MPa }\end{array}$ & $\begin{array}{c}\text { Shear strength/ } \\
\mathrm{MPa}\end{array}$ & $\begin{array}{c}\text { Friction } \\
\text { angle } /{ }^{\circ}\end{array}$ \\
\hline $\begin{array}{l}\text { Beibei } \\
\text { limestone }\end{array}$ & 31.2 & 0.171 & 2600 & 105.95 & 6.76 & 17.72 & 43.62 \\
\hline
\end{tabular}

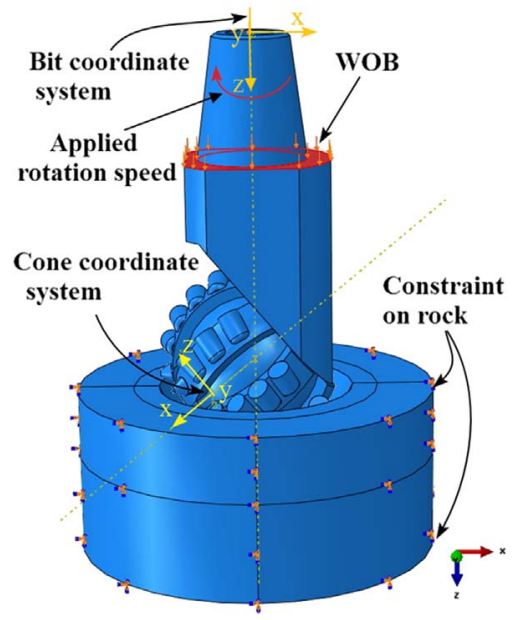

Fig. 21. Boundary setting of rock-breaking simulation.

$\eta=5^{\circ}, \delta=38^{\circ}, r_{\mathrm{Q}}=6.72 \mathrm{~mm}$, the nonlinear dynamic finite element model of drill bit-rock system was established in ABAQUS program, as shown in Figure 20a. According to the Saint-Venant principle, the size of the rock is $220 \mathrm{~mm}$ in diameter and $100 \mathrm{~mm}$ in height. To reduce the time of bottom hole formation and make all the cutter interact with the rock earlier, a pre-contact bottom hole is set on the surface of the rock model according to the size of the spherical single-cone bit, as shown in Figure 20b. The 8-node reduced integration element C3D8R with high accuracy, robustness and hourglass control was employed to discrete the rock model, and the rock's area nearby the cutter was finely meshed, the grid size is about $2 \mathrm{~mm}$. The rock-breaking simulation model was totally divided into 912396 elements. And the system of unit (mm-N-s) was applied in the numerical model, while for convenience, results were displayed according to the engineering conventions. The mechanical parameters of the material of the drill bit are listed in Table 1. The mechanical parameters of rock material are listed in Table 2.

As shown in Figure 21, the overall coordinate system of the spherical single-cone PDC compound bit is in the same direction as the global coordinate system. The $z$-axis of the single-cone bit coincides with the rock center axis, and the positive direction of the $z$-axis is the longitudinal movement direction of the single-cone bit, the $x$-axis is horizontal and perpendicular to the $z$-axis, that is, the $x-0-z$ plane is parallel to the surface of the rock model.

The rock-breaking simulation adopts ABAQUS/Explicit analysis method. Non-reflecting boundary and fixed constraint were applied to the rock surfaces except the top one. The contact type between the cutter and rock was eroding

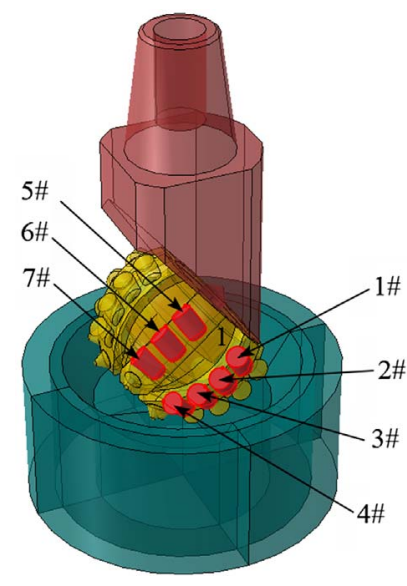

Fig. 22. Number of cutters.

Table 3. Position parameters of PDC cutter.

\begin{tabular}{lccccccc}
\hline Number of cutters & $1 \#$ & $2 \#$ & $3 \#$ & $4 \#$ & $5 \#$ & $6 \#$ & $7 \#$ \\
\hline$h_{\mathrm{C}}(\mathrm{mm})$ & 12.75 & 28.75 & 44.75 & 59 & 16 & 34 & 52 \\
\hline
\end{tabular}

surface to surface. Considering the friction between the cutting surface and rock, the friction coefficient of contact surfaces was set to 0.4 [45]. The simulation loading process is divided into two steps: In the first step, the Weight On Bit (WOB) is $100 \mathrm{~kg}$, which is applied to the upper surface of the bit leg to keep the cutter in contact with the rock. In the second step, the WOB is $2000 \mathrm{~kg}$, which is applied to the upper surface of the bit leg (Fig. 21); at the same time, the rotation speed applied to the center axis of the bit is $60 \mathrm{r} / \mathrm{min}$, so that the single-cone bit rotates at a uniform speed around the center axis of the rock model. Set the simulation time to 6 seconds. The single-cone bit designed in Figure 3 has 25 PDC cutters distributed. Due to the large number of cutting teeth, according to the distribution of $\mathrm{PDC}$ cutter on the surface of the cone, seven representative PDC cutters are selected for research, and their distribution positions on the cone are shown in Figure 22. The position height $h_{\mathrm{C}}$ of the seven PDC cutters are shown in Table 3.

\subsection{Results and discussion}

The equivalent plastic strain cloud diagram of the rock in the simulation of rock-breaking with a spherical single-cone PDC compound bit within 1-6 s is shown in Figure 23. It can be seen from Figure 23 that as the working time of the spherical single-cone PDC compound bit increases, a complete spherical bottom hole is gradually formed in the center of the rock model. 


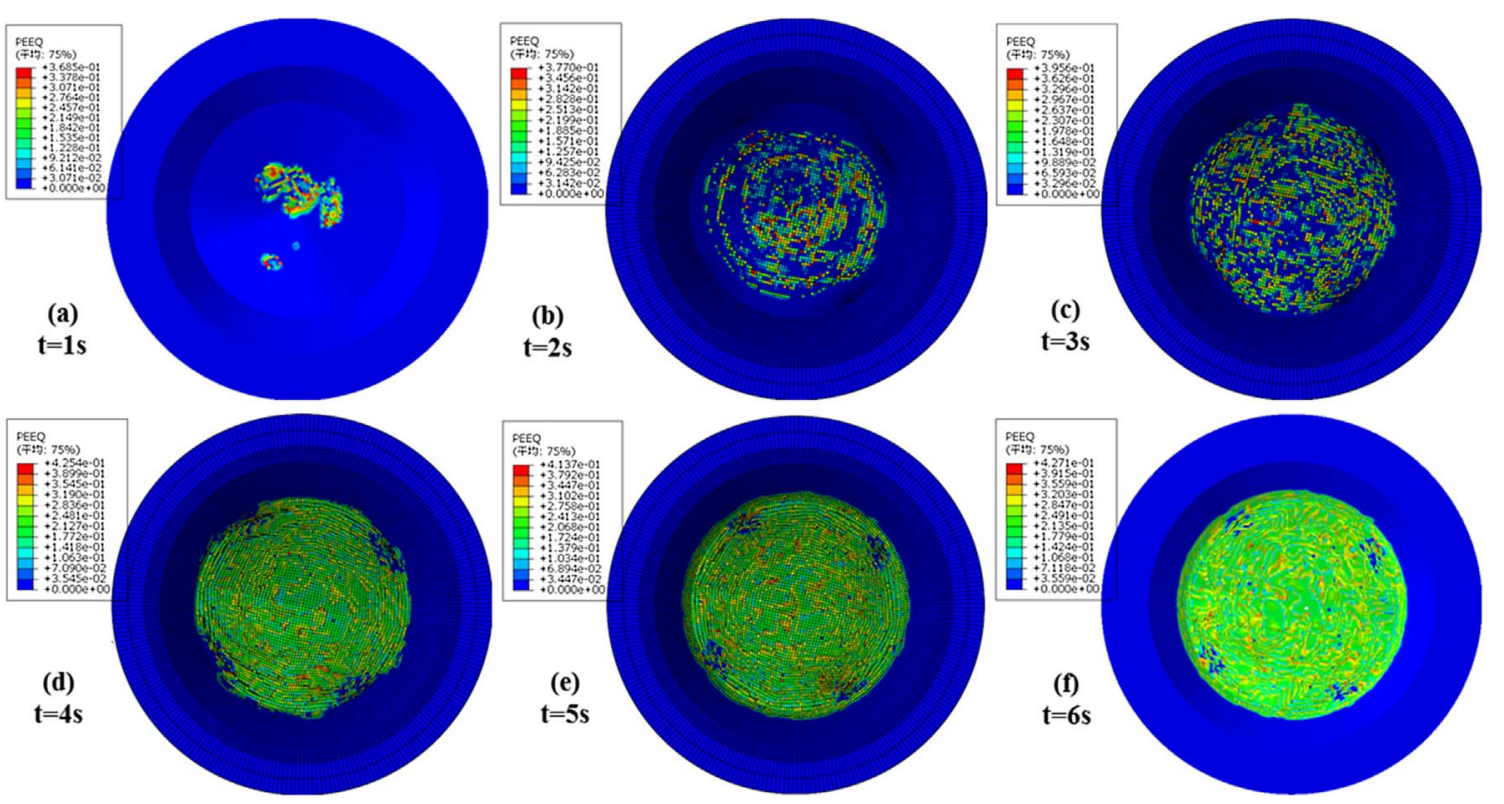

Fig. 23. Equivalent plastic strain in rock-breaking process.

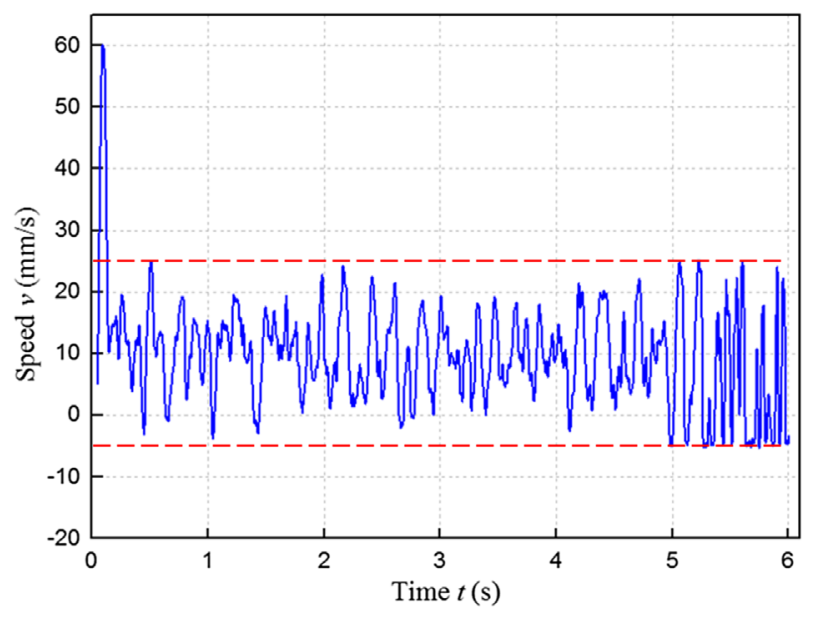

Fig. 24. Longitudinal moving speed of bit.

During the rock-breaking process, the overall longitudinal velocity and acceleration of the drill bit (in the direction of the borehole axis) vary with the drilling time as shown in Figures 24 and 25. It can be seen from Figure 24 that the longitudinal movement speed of the bit fluctuates in the range of -5 to $25 \mathrm{~mm} / \mathrm{s}$. Figure 25 shows that during the rock-breaking simulation of a single-cone bit, the acceleration of the bit fluctuates in the range of $-2500 \sim 2500$ $\mathrm{mm} / \mathrm{s}^{2}$, and the acceleration of most of the time is between $-1000 \sim 1000 \mathrm{~mm} / \mathrm{s}^{2}$. The fluctuation of the speed and acceleration is due to the interaction between the bit and the rock during the rock-breaking process of the single-cone bit, which causes the bit to be accompanied by axial vibration during the drilling process. Therefore, the acceleration of the drill bit has a large extreme value at a certain moment, which is related to the unique rock-breaking method of the single-cone bit.

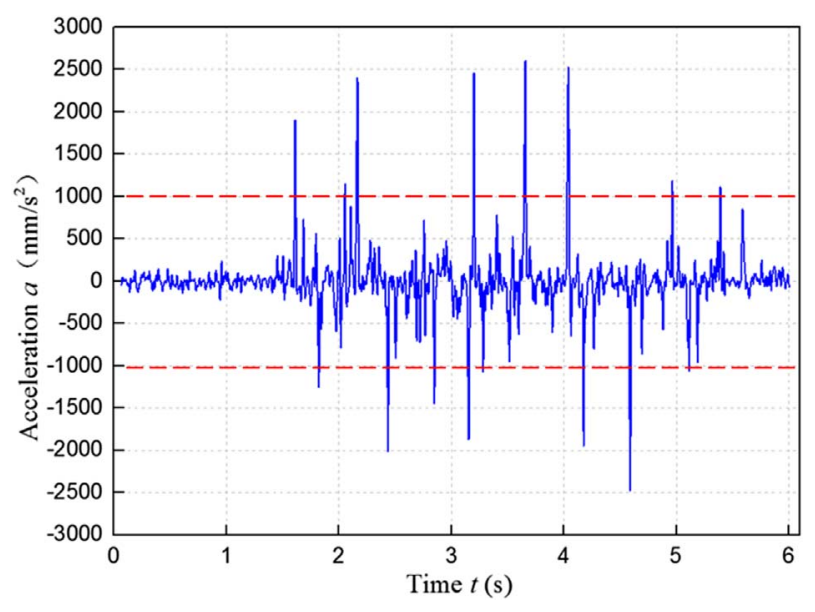

Fig. 25. Longitudinal moving acceleration of bit.

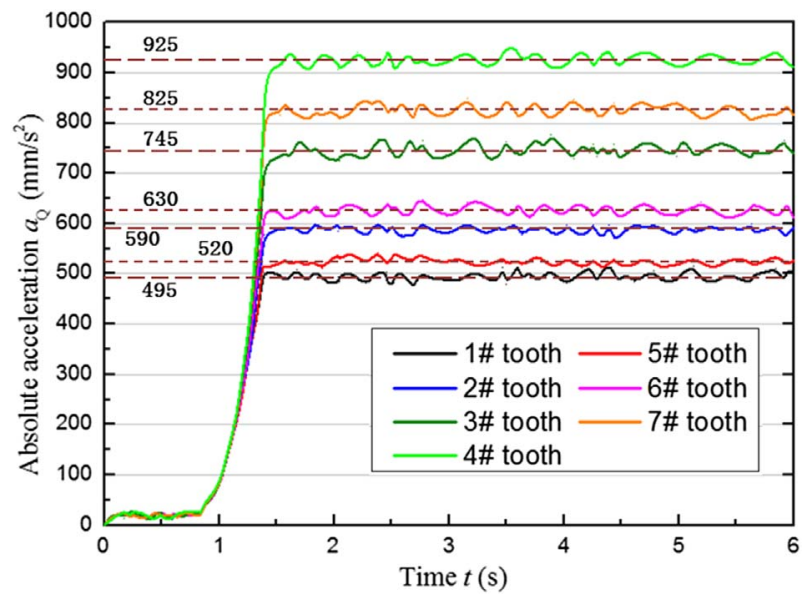

Fig. 26. Absolute acceleration of PDC cutters. 
Table 4. Theoretical and simulated values of PDC cutter acceleration.

\begin{tabular}{lccccccc}
\hline Number of cutters & $1 \#$ & $2 \#$ & $3 \#$ & $4 \#$ & $5 \#$ & $6 \#$ & $7 \#$ \\
\hline Theoretical value $\left(\mathrm{mm} / \mathrm{s}^{2}\right)$ & 486.2 & 580.9 & 734.2 & 904.7 & 508.6 & 621.9 & 817.2 \\
Simulation average value $\left(\mathrm{mm} / \mathrm{s}^{2}\right)$ & 495 & 590 & 745 & 925 & 520 & 630 & 825 \\
Fractional error $(\%)$ & -1.81 & -1.57 & -1.47 & -2.24 & -2.24 & -1.31 & -0.95 \\
\hline
\end{tabular}

The acceleration simulation data of these seven PDC cutters is shown in Figure 26. It can be seen from Figure 26 that as the drilling time increases, the acceleration of the PDC cutter at each position on the surface of the cone gradually increases. After $1 \mathrm{~s}$, the acceleration value suddenly increases, and the acceleration of the seven PDC cutters reaches the maximum when approaching $1.5 \mathrm{~s}$. After $1.5 \mathrm{~s}$, the acceleration of each PDC tooth is in a small fluctuation, but the overall trend is stable. The reason for the acceleration fluctuation in the simulation experiment is that the cone rotates around the cone axis during the drilling process of the single-cone bit, and generates rolling rock-breaking, which in turn causes the bit to vibrate, and ultimately causes the acceleration of the PDC cutter to fluctuate. The acceleration of the $4 \#$ tooth is greater than that of the 1 \# tooth, which is consistent with the analysis results of Figures 12 and 14. According to the acceleration fluctuation curve after $1.5 \mathrm{~s}$ in Figure 26, the average curve of each PDC tooth is made, and the theoretical calculation value in Figure 14 is compared with the simulation experiment average value in Figure 26 (Tab. 4). Table 4 shows that the acceleration values of the PDC cutter obtained through the simulation experiment are all greater than the theoretical calculation values, and the fractional error between the theoretical analysis results of the acceleration of the PDC cutter and the simulation experiment results is between $-0.95 \%$ and $-2.24 \%$. This shows that this paper is advisable to study the acceleration theory of the spherical single-cone PDC compound bit.

\section{Conclusion}

In this paper, the acceleration equation of the spherical single-cone PDC compound bit is established; sandstone, limestone and granite are selected respectively, and the acceleration of the spherical single-cone PDC compound bit is quantitatively analyzed and calculated; the acceleration of the single-cone bit is verified by numerical simulation experiment of rock-breaking, with the following conclusions drawn.

The bit transmission ratio $i$ increases as the shaft inclination angle $\beta$ increases, and the harder the rock formation, the larger the single-cone bit transmission ratio $i$; the rock formation has an influence on the acceleration of the cutting teeth, and the acceleration of the cutting teeth in the hard rock layer is higher than that in the soft rock layer.

The shaft inclination angle and the position height of the PDC teeth have a greater impact on the acceleration of the PDC teeth, and close to the top of the cone, the absolute acceleration of the cutting teeth will fluctuate sharply and cause severe wear of the cutting teeth; the greater $\beta$, the closer the absolute acceleration fluctuation position is to the top of the cone, and the smaller the fluctuation amplitude; the absolute acceleration decreases as $\beta$ increases, which means that the inertial force of the drill bit is smaller; however, considering the wear of the cone bearing, the shaft inclination angle $\beta$ of the single-cone bit cannot be designed too large; on the premise that the bearing life of the single-cone bit is allowed, the value of $\beta$ can be approached to $70^{\circ}$.

The relative error between the theoretical analysis results of the acceleration of the PDC cutter and the rock-breaking simulation experiment results is between $-0.95 \%$ and $-2.24 \%$. This shows that this paper is advisable to study the acceleration theory of the spherical single-cone PDC compound bit.

Acknowledgments. This research work was supported by the Key Scientific Research Fund of Xihua University (No. Z17119-0303); Research Project of Key Laboratory Machninery and Power Machinery (Xihua University), Ministry of Education.

\section{References}

1 Deng R., Yang S.L., Yu K.A. (1995) Study of single spherieal roller bit, J. Southwest Pet. Univ. 17, 1, 96-100. (in Chinese).

2 Langford J.W.J. (1997) One-cone bits improve efficiency of drilling small diameter holes, Pet. Eng. Int. 72, 2, 23-28.

3 Witman G.B., Wilson P., Mcdonough S.D., Siracki M.A. (2008) Single cone rock bit having inserts adapted to maintain hole gage during drilling, US, 7100711.

4 Moran D.P., Witman Iv G.B. (2004) One cone bit with interchangeable cutting structures, a box-end connection, and integral sensory devices, US, US6814162 B2.

5 Fletcher S. (2003) Custom designed single-cone bit works for well of Albania, Oil Gas J. 101, 44-45.

6 Chen L., Yang Y.X., Xie Z.L., Ren H.T., Yang L.Y. (2020) Rotating cutter single cone bit, US, US2020217141A1.

7 Yu K.A., Deng R., Ma D.K. (1995) Rock disintegrating track of spherical mono-cone bit, China Pet. Mach. 23, 4, 1-7. (in Chinese).

$8 \mathrm{Hu}$ Q., Liu Q.Y. (2006) A new disc one-cone bit, IADC/SPE 102381-MS.

9 Huang H.M., Beijing Liu X.Z., Sun H. (2003) Development of slim hole single cone bit, China Pet. Mach. 31, 12, 40-41. (in Chinese).

10 Huang H.M., Liu X.Z., Sun H., Zhai Y.H., Zhao H. (2003) Research and application of small size series single roller bit, China Pet. Mach. 31, 12, 40-41. (in Chinese).

11 Kong C.Y., Liang Z., Zhang D.R. (2017) Failure analysis and optimum structure design of PDC cutter, Mechanika 23, 4, 567-573. https://doi.org/10.5755/j01.mech.23.4.14932.

12 Miller G., Dewey C., Saylor J. (1997) Sidetracking in a single trip. Society of Petroleum Engineers. 
$13 \mathrm{Yu}$ Z.Q., Zhang J.S. (1998) Research on development prospect of single-roller bit, Fault-Block Oil Gas Field 5, 6, $48-51$.

14 Ma D.K. (2009) The operational mechanics of the rock bit, Petroleum Industry Press, Beijing. (in Chinese).

15 Wang Z.G., Deng R., Yang G. (2007) The computer simulation model study of singular one-cone bit, Oil Field Equip. 36, 3, 26-29. (in Chinese).

16 Deng R., Ao J.Z., Yang S., An M. (2014) Rock breaking simulation and cutter selection of the special single cone bit, China Pet. Mach. 12, 11-16. (in Chinese).

17 Li K.R. (2018) Research and application of new type single cone bit, Mod. Manuf. Technol. Equip. 2, 41-42. (in Chinese).

$18 \mathrm{Yu}$ K.A., Ding L.P. (2009) Study of kinematics of offset single cone bit, China Pet. Mach. 37, 1, 1-4. (in Chinese).

$19 \mathrm{Yu}$ K.A. (2009) Study on dynamics of single cone bit, Oil Field Equip. 38, 2, 11-14. (in Chinese).

20 Deng R., Yu K.A., Yang S.L. (1995) Geometry and bottom hole track of single cone bit, Oil Field Equip. 24, 5, 14-17. (in Chinese).

21 Pessier R., Damschen M. (2011) Hybrid bits offer distinct advantages in selected roller-cone and PDC bit applications, SPE Drill. Complet. 26, 1, 96-103.

22 Moujbani W., Aliko E., Chaabane N. (2014) Development of a PDC-tricone hybrid technology to solve drilling problems of surface holes in North Africa, in: Offshore Technology Conference-Asia.

23 Miao S., Blackman M., Luo J., Luo L. (2016) Hybrid bit produces breakthrough performance in heterogeneous formations in China, in: Offshore Technology Conference Asia.

24 Hurlburt M., Quintero J., Bradshaw R., Belloso A., Glass D. (2019) Combining state-of-the-art hybrid bit and positive displacement motors saves 863,670 CAD over 20 wells in Northern Alberta, Canada, in: SPE Oklahoma City Oil and Gas Symposium.

25 Chowdhury A.R., Serrano R., Rodrigue W. (2019) Pilot bit and reamer matching: real-time downhole data differentiates hybrid drill bit's suitability with concentric reamer in deepwater, Gulf of Mexico application, in: $S P E / I A D C$ International Drilling Conference and Exhibition.

26 Zhang Y.H., Baker R., Burhan Y., Shi J., Chen C., Tammineni S., Durairajan B., Self J., Segal S. (2013) Innovative rolling PDC cutter increases drilling efficiency improving bit performance in challenging applications, in: SPE/IADC 163536, 5-7 March.

27 Giumelli M., O'Shea P., Maliardi A., Sosnowski P., Shepherd A., Sadawarte S.S., Maurizio S. (2014) Offshore exploration program benefits from rolling PDC cutter Technology, in: Timor Sea Australia, IADC/SPE-170532-MS, 25-27 August.

28 Kim E., Rostami J., Swope C. (2009) Measurement of Conical Bit Rotation, in: US Rock Mechanics Symposium 83 US-Canada Rock Mechanics Symposium.
29 Iskandar F.F., Fanti D., Liang T.T. (2016) Innovative conical diamond element bits deliver superior performance drilling a geothermal well in the Philippines, in: OTC-26421MS, 22-25 March.

30 Pak M., Azar M., Bits S., PahI J. (2016) Conical diamond element enables PDC bit to efficiently drill chert interval at high ROP replacing turbine/impregnated BHA, in: IADC/ SPE-178765-MS, 1-3 March.

31 Chen L., Yang Y.X., Lin M., Ren H.T. (2013) Composite single cone bit, China Patent No. ZL 2010106143706. (in Chinese).

32 Yang Y.X., Chen L., Lin M., Pei Z., Ren H.T. (2013) Scraping-wheel drill bit, US20130126246.

33 Yang Y.X., Chen L., Lin M. (2015) Composite drill bit, WO2012006966 A1.

34 Chen L., Yang Y.X., Liu Y., Lin M., Zhang C.L., Niu S.W. (2017) The operational theory and experimental study of scraping-wheel diamond bit, J. Pet. Sci. Eng. 156, 152-159. https://doi.org/10.1016/j.petrol.2017.04.043.

35 Yang Y., Zhang C., Chen L., Liu Y. (2017) Kinematic and bottom-hole pattern analysis of a composite drill bit of crossscraping, Proc. Inst. Mech. Eng. C 231, 17, 3104-3117. https://doi.org/10.1177/0954406216642797.

36 Yang Y.X., Zhang C.L., Lin M., Chen L. (2018) Research on rock-breaking mechanism of cross-cutting PDC bit, J. Pet. Sci. Eng. 161, 657-666. https://doi.org/10.1016/j.petrol.2017. 11.034 .

37 Yang Y.X., Kuang Y.C., Chen L., Ren H.T. (2010) Progress and development direction of rock breaking technology, in: Oil and Gas Drilling, Tenth Conference of Oil drilling Dean and Institute director, China Petroleum Institutepp. 154-160 (in Chinese).

38 Yang Y.X. (2003) Research on mechanics of PDC bit rock cutting process, PhD Thesis. Southwest Petroleum University, Chengdu. (in Chinese).

39 Deng R., Yang S.L., Yu K.A. (1995) Test and analysis of transmission ratio of mono-cone bits, China Pet. Mach. 23, 6, 14-17. (in Chinese).

40 Wu K.S., Ma D.K. (2001) Particularity and main research direction of roller cone bit plain bearing, China Pet. Mach. 29, 004, 52-54. (in Chinese).

41 Wang G.R., Zheng J.W., Kang Q.J. (2006) Failure analysis of rock bit journal bearings, Lubr. Eng. 10, 22-24.

42 Zhu X.H., Yi Q.J. (2018) Research and application of reaming subsidence control in horizontal directional drilling, Tunn. Undergr. Space Technol. 75, 1-10. (in Chinese).

43 Zhang M., Wang F., Yang Q. (2013) Statistical damage constitutive model for rocks based on triaxial compression tests, Chinese J. Geotech. Eng. 35, 11, 1965-1971.

44 Ouyang Y.P., Yang Q. (2016) Numerical simulation of rock cutting in 3D with SPH method and estimation of cutting force, J Shanghai Jiaotong Univ. 50, 1, 84-90. (in Chinese).

45 Jaime M.C., Zhou Y., Lin J.S., Gamwo I.K. (2015) Finite element modeling of rock cutting and its fragmentation process, Int. J. Rock Mech. Min. Sci. 80, 137-146. 